\title{
A Comparison of the Finescale Structures of a Prefrontal Wind-Shift Line and a Strong Cold Front in the Southern Plains of the United States ${ }^{\mathscr{D}}$
}

\author{
HowArd B. Bluestein, ${ }^{\mathrm{a}}$ ZACHARy B. Wienhoff, ${ }^{\mathrm{a}}$ DAVID D. TuRner, ${ }^{\mathrm{b}}$ Dylan W. Reif, \\ JEFFREY C. SNYDER, ${ }^{\mathrm{c}}{ }^{\text {K YLE J. THIEM, }}{ }^{\mathrm{a}}$ AND JANA B. HOUSER ${ }^{\mathrm{d}}$ \\ ${ }^{\text {a }}$ School of Meteorology, University of Oklahoma, Norman, Oklahoma \\ ${ }^{\mathrm{b}}$ NOAA/National Severe Storms Laboratory, Norman, Oklahoma \\ ${ }^{\mathrm{c}}$ Cooperative Institute for Mesoscale Meteorological Studies, University of Oklahoma, and NOAA/OAR/National \\ Severe Storms Laboratory, Norman, Oklahoma \\ ${ }^{\mathrm{d}}$ Department of Geography, Ohio University, Athens, Ohio
}

(Manuscript received 20 October 2016, in final form 14 April 2017)

\begin{abstract}
The objectives of this study are to determine the finescale characteristics of the wind and temperature fields associated with a prefrontal wind-shift line and to contrast them with those associated with a strong cold front. Data from a mobile, polarimetric, X-band, Doppler radar and from a surveillance S-band radar, temperature profiles retrieved from a thermodynamic sounder, and surface observations from the Oklahoma Mesonet are used to analyze a prefrontal wind-shift line in Oklahoma on 11 November 2013. Data from the same mobile radar and the Oklahoma Mesonet are used to identify the finescale characteristics of the wind field associated with a strong surface cold front in Oklahoma on 9 April 2013. It is shown that the prefrontal wind-shift line has a kinematic and thermodynamic structure similar to that of an intrusion (elevated density current), while the cold front has a kinematic structure similar to that of a classic density current. Other characteristics of the prefrontal wind-shift line and front are also discussed. Evidence of waves generated at the leading edge of the prefrontal wind-shift line is presented.
\end{abstract}

\section{Introduction}

Cold fronts that form at the surface purely as the response to geostrophic deformation acting on a temperature gradient ("classical fronts") are characterized by a cyclonic and convergent wind-shift line marked by a pressure trough, and a baroclinic (frontal) zone that resides just on the cold side of the wind-shift line (Keyser 1986; Bluestein 1993). Prefrontal, surface windshift lines (Sanders and Doswell 1995; Schultz 2008: Schultz and Roebber 2008) with associated surface pressure troughs (but no well-defined baroclinic zone) are features that form when surface cold fronts interact with orography (e.g., Hutchinson and Bluestein 1998). They frequently accompany cold fronts in the plains of the central United States, east of the Rocky Mountains

Supplemental information related to this paper is available at the Journals Online website: http://dx.doi.org/10.1175/ MWR-D-16-0403.s1.

Corresponding author: Howard B. Bluestein, hblue@ou.edu
(Fig. 1), and are sometimes associated with a lee trough or dryline. The convergence zone along the wind-shift line is sometimes the location of convection initiation. Oftentimes, the passage of the cold front that follows the prefrontal wind-shift line is unlike that of a classical front (e.g., Keyser 1986: Bluestein 1993) because there is no cyclonic wind shift across it. Sanders (1999) refers to these cold fronts as "nonfrontal baroclinic zones." Prefrontal surface troughs have also been documented in Australia (Hanstrum et al. 1990).

Schultz (2005) presented an extensive review of 10 different mechanisms that may be responsible for the prefrontal wind-shift line phenomenon. Some are external to the cold front, such as the environment; for example, synoptic-scale forcing (e.g., Cunningham and Keyser 1999), and bores and other gravity waves generated ahead of the front in stable, low-level air, can induce wind shifts (e.g., Koch and Clark 1999) that can play a role in the formation of prefrontal wind-shift lines. Hartung et al. (2010), for example, found that a bore triggered by a cold front propagated ahead of the front and was thus responsible for the separation 


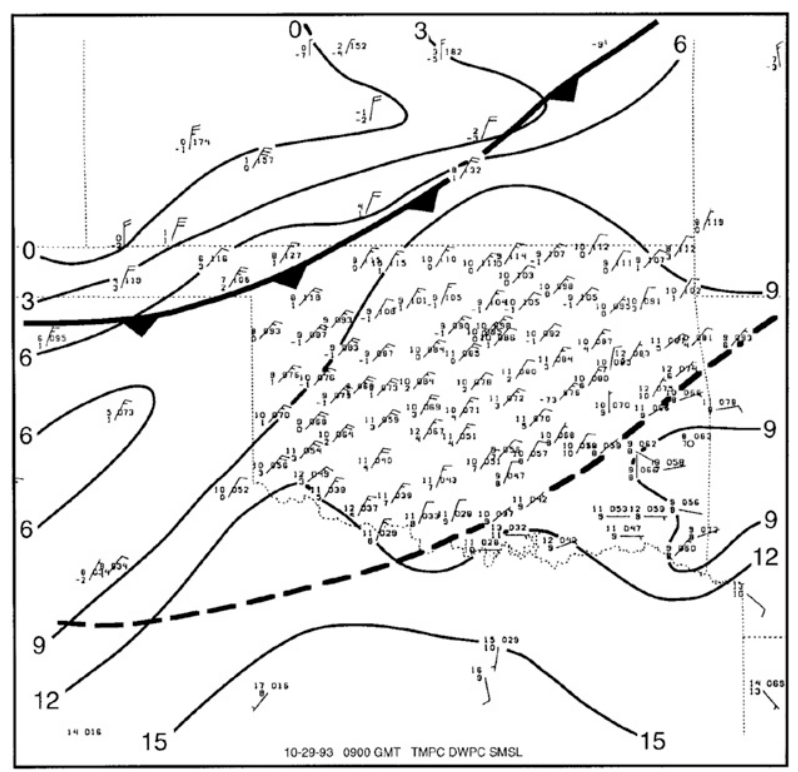

FIG. 1. An example of a prefrontal wind-shift line in the southern plains of the United States [Fig. 9 from Hutchinson and Bluestein (1998)] on 29 Oct 1990. The cold front symbol is conventional; the dashed line represents the prefrontal wind-shift line. Temperature and dewpoint are plotted in ${ }^{\circ} \mathrm{F}$; whole wind barb $=5 \mathrm{~m} \mathrm{~s}^{-1}$ and half wind barb $=2.5 \mathrm{~m} \mathrm{~s}^{-1}$.

between the wind-shift line and the (trailing) cold front. As the bore decayed, the cold front caught up with the wind-shift line.

Some mechanisms are internal, such as surface friction, which can result in a nose of overhanging cold advection (Brunt 1934; Shapiro 1984). While there have been a number of observational studies of the finescale structure of nonprecipitating fronts using recording instruments (e.g., Martin 1973), some of which were mounted on towers (e.g., Brunt 1934; Shapiro 1984), and using radars (e.g., Ligda and Bigler 1958; Wakimoto and Cai 2002; Stonitsch and Markowski 2007), to the best of our knowledge there are no such studies of the finescale structure of prefrontal windshift lines.

Mobile Doppler radars have been used for over 20 years to study severe convective storms and tornadoes because they provide very high spatial resolution when they are deployed near storms (e.g.,Wurman and Gill 2000; Bluestein and Pazmany 2000), but have been much less commonly used to study fronts (e.g., Ziegler et al. 2007). When the Advanced Radar Research Center (ARRC) at the University of Oklahoma (OU), Norman, Oklahoma, obtained a rapid-scan, polarimetric, X-band, mobile Doppler radar in 2011 (Pazmany et al. 2013), it became possible for the first time to collect serendipitous mobile Doppler radar data near OU on weather phenomena during the cold season, when the radar was not otherwise being used to probe severe convective storms. On 11 November 2013, such a dataset was collected when a prefrontal wind-shift line propagated through Norman. On 9 April 2013, during the beginning of our spring storm-season field program, data were collected across a strong cold front passing by the mobile radar site in southwestern Oklahoma, when severe convective storms failed to form in our target area. The main purpose of this paper is to describe the finescale vertical structure of the prefrontal wind-shift line observed on 11 November 2013 and to contrast its structure with that of the classical cold front observed on 9 April 2013, which did not have any prefrontal windshift line associated with it. While mobile Doppler radar data were the primary sources of information, thermodynamic data from an instrument mounted on the roof of the National Weather Center (NWC) in Norman were also available for the former case. A secondary purpose of this study is to speculate why prefrontal wind-shift lines are usually not characterized by strong baroclinicity at the surface, but have cyclonic vorticity and convergence, while the trailing cold front is not characterized by cyclonic vorticity, as are classic cold fronts.

\section{Data sources and analysis}

The primary sources of data were the Oklahoma Mesonet (Brock et al. 1995; McPherson et al. 2007), the mobile rapid-scan X-band polarimetric Doppler radar (RaXPol; Pazmany et al. 2013), and an Atmospheric Emitted Radiance Interferometer (AERI; Turner et al. 2000; Knuteson et al. 2004). Data from the Twin Lakes (KTLX) WSR-88D S-band (10-cm wavelength) surveillance radar (Crum and Alberty 1993) were also used to provide a larger-scale context for the RaXPol and AERI measurements. The reader is referred to appendix A for a figure showing all significant locations referred to hereafter.

\section{a. Oklahoma Mesonet}

The Oklahoma Mesonet (hereafter referred to as the "mesonet") is a network of 121 (as of September 2016) recording, meteorological instruments mounted on or located near a $10-\mathrm{m}$ tall tower. There is at least one station in each of Oklahoma's 77 counties. It provides measurements every $5 \mathrm{~min}$ of various meteorologically relevant quantities that can be used for mesoscale analysis, including temperature, dewpoint, wind direction and speed, pressure, precipitation, and solar radiation. (Details on the actual instrumentation, data validation, and accuracy of the 
instrumentation can be found online at http://www. mesonet.org and other publications linked to this website).

\section{b. RaXPol}

RaXPol has been used mainly for studies of severe convective storms and tornadoes (e.g., Pazmany et al. 2013; Snyder and Bluestein 2014: Bluestein et al. 2015; Houser et al. 2015). Details about the instrument and its operation and accuracy can be found in the aforementioned references. The rapidscan capabilities afforded by frequency hopping and with a high-speed pedestal are not required for more slowly evolving, mesoscale features such as fronts and prefrontal wind-shift lines. When scanning more slowly, however, the radar can provide improved estimates of radar reflectivity factor $Z_{\mathrm{H}},{ }^{1}$ Doppler velocity $V$, and polarimetric variables (used to infer the nature of the scatterers; a detailed discussion of the relationship between the polarimetric variables and type of scatterers is found in appendix B) owing to higher pulse sample averaging that results from reduced correlation between transmitted pulse pairs that are shifted in frequency; averaging more quasi-independent samples of the received signal reduces the variance of the estimates of the radar quantities [e.g., refer to section 6.5.2 in Bringi and Chandrasekar (2001) and chapter 6 in Doviak and Zrnić (1993)]. Furthermore, for "clear air" operation, when radar backscattering is mainly from insects or dust (often moderate to very low $Z_{\mathrm{H}}$, e.g., $<30 \mathrm{~dB} Z$ ) instead of moderate or heavy precipitation observed in supercells (often moderate to high $Z_{\mathrm{H}}$, e.g., $30-60^{2} \mathrm{~dB} Z$ ), the sensitivity of the radar is increased by lengthening the pulse width (which is directly proportional to the return power) from a typical length of $0.2-0.5 \mu \mathrm{s}$ (corresponding to a range resolution of $30-75 \mathrm{~m}$ ) to a length closer to 1$2 \mu \mathrm{s}$ (corresponding to range resolution of $150-300 \mathrm{~m}$ ), especially when the fine line is farthest from the radar.

RaXPol was deployed from a location several kilometers east of the NWC in Norman, where beam blockage was relatively low compared to other nearby locations on the OU campus, but near enough to the NWC so that measurements made at the NWC were close to what was probably experienced at the radar site.

\footnotetext{
${ }^{1}$ The terms $Z$ and $Z_{\mathrm{H}}$ are used interchangeably. When a radar has polarimetric capabilities, the subscript " $H$ " is often used for clarity.

${ }^{2}$ This range is for an $\mathrm{X}$-band radar; for an S-band radar, $Z_{\mathrm{H}}$ can be $>70 \mathrm{~dB} Z$.
}

To examine the finescale structure of the wind field about the prefrontal wind-shift line at constant altitude, dual-Doppler analyses of the wind field were created from Doppler wind data from RaXPol and KTLX (appendix C).

\section{c. $A E R I$}

The AERI is a high-spectral resolution sounder designed and built at the University of WisconsinMadison (Turner et al. 2000; Knuteson et al. 2004). It is an "automated ground-based passive infrared interferometer that measures downwelling atmospheric radiance from 3.3 to $18.2 \mu \mathrm{m}\left(550-3000 \mathrm{~cm}^{-1}\right)$ every $8 \mathrm{~min}$ with a spectral resolution of $0.5 \mathrm{~cm}^{-1}$ ", (Turner et al. 2000, p. 1302). AERIs were modified to collect higher temporal observations ( $\sim 30 \mathrm{~s})$ and a principle component noise filter is used to reduce the random errors in the observed spectra to acceptable levels (Turner et al. 2006). More details on the instrument and its operation are found in Turner et al. (2000), Turner and Löhnert (2014), and at other references noted in the aforementioned.

Because spectral downwelling infrared radiance is sensitive to the temperature and moisture profiles in the vertical, temperature (and moisture content) as a function of height may be retrieved. We used the physical-iterative algorithm of Turner and Löhnert (2014) to retrieve profiles of temperature and humidity from the AERI. This algorithm currently requires an estimate of the cloud-base height (if there are clouds overhead) to help the retrieval separate out the contribution from the clouds versus the atmospheric structure to the downwelling infrared radiance. Temperature is estimated from the surface to above $\sim 2 \mathrm{~km}$ with an estimated bias of $0.2 \mathrm{~K}$ under clear-sky conditions and maximum rootmean-square error $<1 \mathrm{~K}$ (Turner and Löhnert 2014). Under cloudy conditions, the accuracy is less (i.e., the RMS error greater) owing to the added uncertainty in separating the emission from the cloud in the retrieval algorithm (Blumberg et al. 2015). The vertical resolution of the AERI varies approximately linearly with height, from less than $20 \mathrm{~m}$ at the surface to $2 \mathrm{~km}$ at $1.5 \mathrm{~km}$ AGL. The horizontal resolution is the $2^{\circ}$ pencil beam smeared as features are advected over the 5 -min averaging period, which is $\sim 3 \mathrm{~km}$.

The AERI was located on the roof of the 30-35-mhigh NWC building. Since it was close (within $\sim 3-$ $4 \mathrm{~km}$ ) to the location of RaXPol, we can assume that its measurements and those of RaXPol are representative of approximately the same location. The small difference in location may account for some 


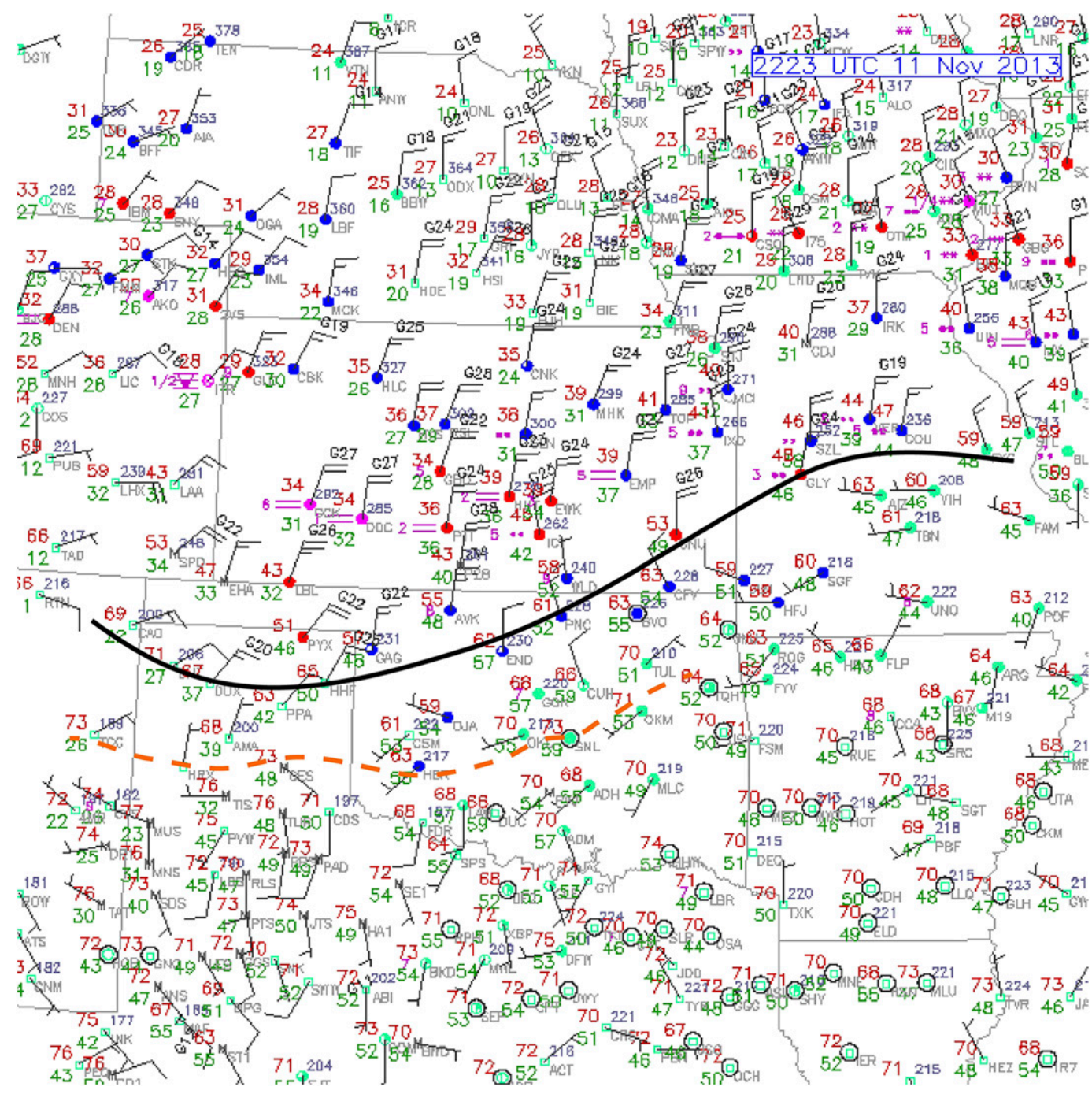

FIG. 2. Plotted surface observations on 11 Nov 2013, with the cold front (solid black line) and prefrontal windshift line (dashed red line) analyzed: (a) regional map (2223 UTC) and (b) Oklahoma Mesonet map (2225 UTC). Temperature and dewpoint are plotted in ${ }^{\circ} \mathrm{F}$; whole and half wind barbs represent 5 and $2.5 \mathrm{~m} \mathrm{~s}^{-1}$, respectively.

errors in quantitative interpretation, but not qualitative interpretation.

\section{The prefrontal wind-shift line of 11 November 2013}

\section{a. Synoptic and mesoscale analysis}

Late in the afternoon of 11 November 2013 an eastnortheast-west-southwest-oriented surface cold front entered Oklahoma from Kansas (Fig. 2a). Strong northnortheasterly winds of $10-12.5 \mathrm{~m} \mathrm{~s}^{-1}$ were located over much of Kansas, where surface temperatures were generally $\sim 2^{\circ}-6^{\circ} \mathrm{C}\left(34^{\circ}-43^{\circ} \mathrm{F}\right)$, while in most of Oklahoma temperatures were $\sim 16^{\circ}-21^{\circ} \mathrm{C}\left(60^{\circ}-70^{\circ} \mathrm{F}\right)$; in northeastern Oklahoma, ahead of the cold front but behind the prefrontal wind-shift line (PWL) winds generally had a northerly component, while in much of the rest of the state, ahead of the PWL, winds were weak and had a southerly component.

From the surface mesonet observations (Fig. 2b) it is seen that the passage of the cold front is marked by not only a decrease in temperature but also by an increase in wind speed. Ahead of (to the south of) the front, in a region of much weaker quasi-horizontal temperature gradient, there is a wind-shift line, which extends from far southwestern Oklahoma into central and northeastern Oklahoma. To the rear (poleward) of the cold front and the northern portion of the wind-shift line it was cloudy; in central Oklahoma there were solid-to-broken 


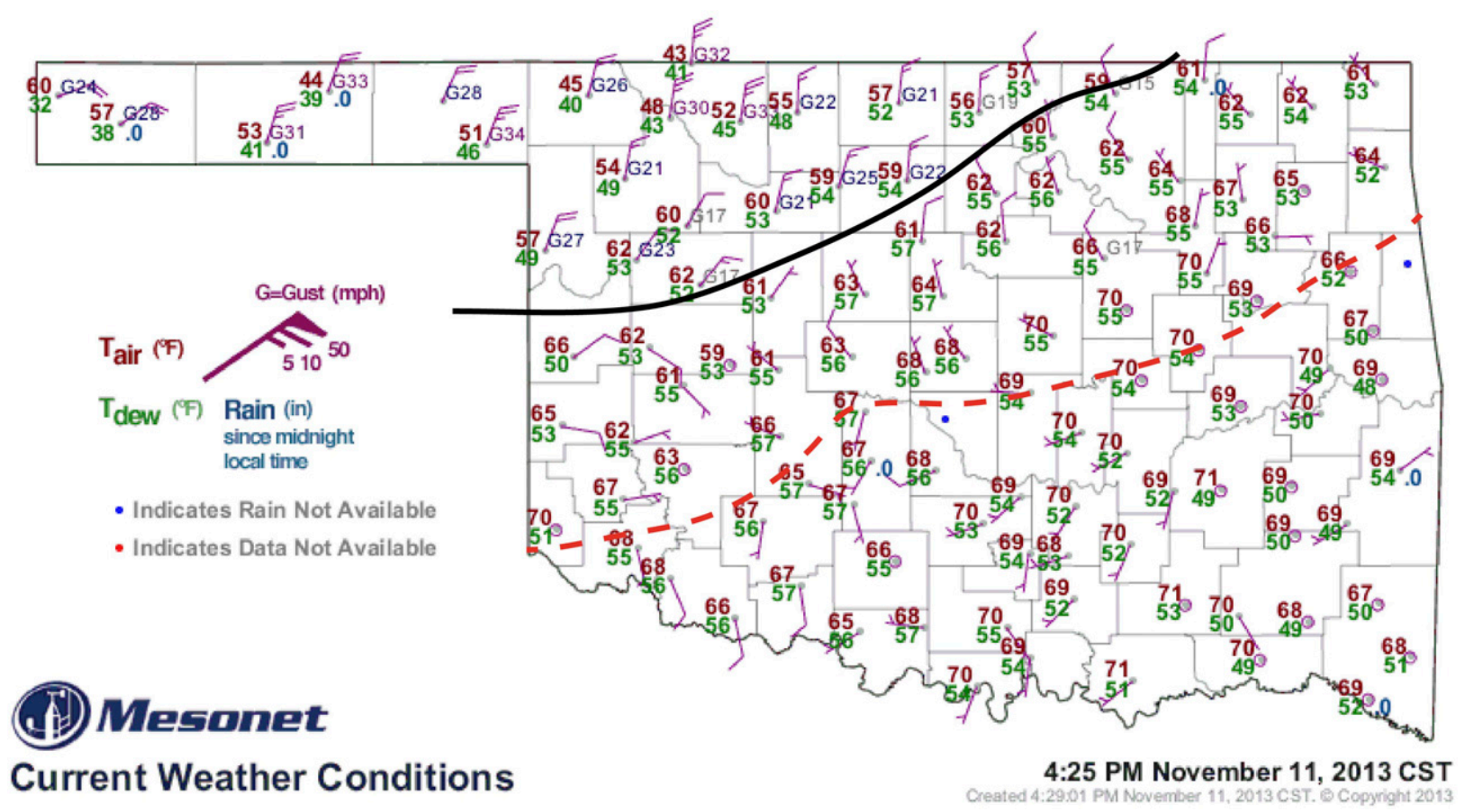

FIG. 2. (Continued)

low clouds, all of which inhibited daytime heating. The solar radiation at Guthrie, Oklahoma, north of Oklahoma City, was only $\sim 200 \mathrm{~W} \mathrm{~m}^{-2}$ or less at the time PWL passed by (Fig. 3a), which is no greater than $1 / 3$ of the approximate climatological maximum. Despite the variation in cloud cover south of the PWL, temperatures were relatively uniform, indicating that it did not have a major effect.

Examples of the temporal variations in temperature, dewpoint, wind direction and speed, and station pressure at two mesonet stations in central Oklahoma (Guthrie and Norman) are shown by meteograms in Fig. 3. This figure illustrates the transition of meteorological variables during the passage of the front and the prefrontal wind shift, which are representative qualitatively of what happened at other stations (not shown). Frontal passage (FROPA) is characterized by a discontinuity (on time scales of tens of minutes) in the first time derivative of temperature, followed by an exponential-like drop in both temperature and dewpoint, as is found in classical fronts (e.g., Bluestein 1993). The dewpoint increased slightly just after the PWL, perhaps as a result of reduced vertical mixing. At the time of frontal passage, the wind speed suddenly increased but the wind direction remained unchanged, unlike the behavior of the wind field when a classical front passes, as noted earlier. At Guthrie, the temperature drop during FROPA actually occurred in two steps separated by about $1 \mathrm{~h}$ (Fig. 3a, first panel); this feature was not found later at Norman during FROPA (Fig. 3b, first panel) and was therefore probably transient. At Guthrie there was a corresponding drop in dewpoint (Fig. 3a, first panel) with sudden bursts of wind (Fig. 3a, second panel) when each temperature drop occurred. The microstructure of the front at Guthrie could have been the result of downward mixing of potentially warmer air that arrested the initial drop in temperature after FROPA.

At Guthrie (Fig. 3a, third panel) there was a minimum in station pressure at approximately the time of the passage of the prefrontal wind-shift line ( 2000 UTC) and the pressure increased most rapidly just following frontal passage $(\sim 0020$ UTC). At Norman (Fig. 3b, third panel) the station pressure minimum ( 2050 UTC) preceded the PWL $(\sim 2350$ UTC $)$ by $\sim 3 \mathrm{~h}$. Thus, there was a surface trough along the PWL at Guthrie, while at Norman the surface trough axis appeared to be ahead of the PWL. At Guthrie (Fig. 3a, bottom panel) there was much less insolation than there was at Norman (Fig. 3b, bottom panel), so it is speculated that from hydrostatic considerations, increased heating ahead of the PWL might have been responsible [cf. the quasigeostrophic omega equation and vorticity equation; Bluestein (1992)] for the apparent displacement of the surface trough to the south. Near Norman, however, the trough was broader and the associated horizontal pressure 


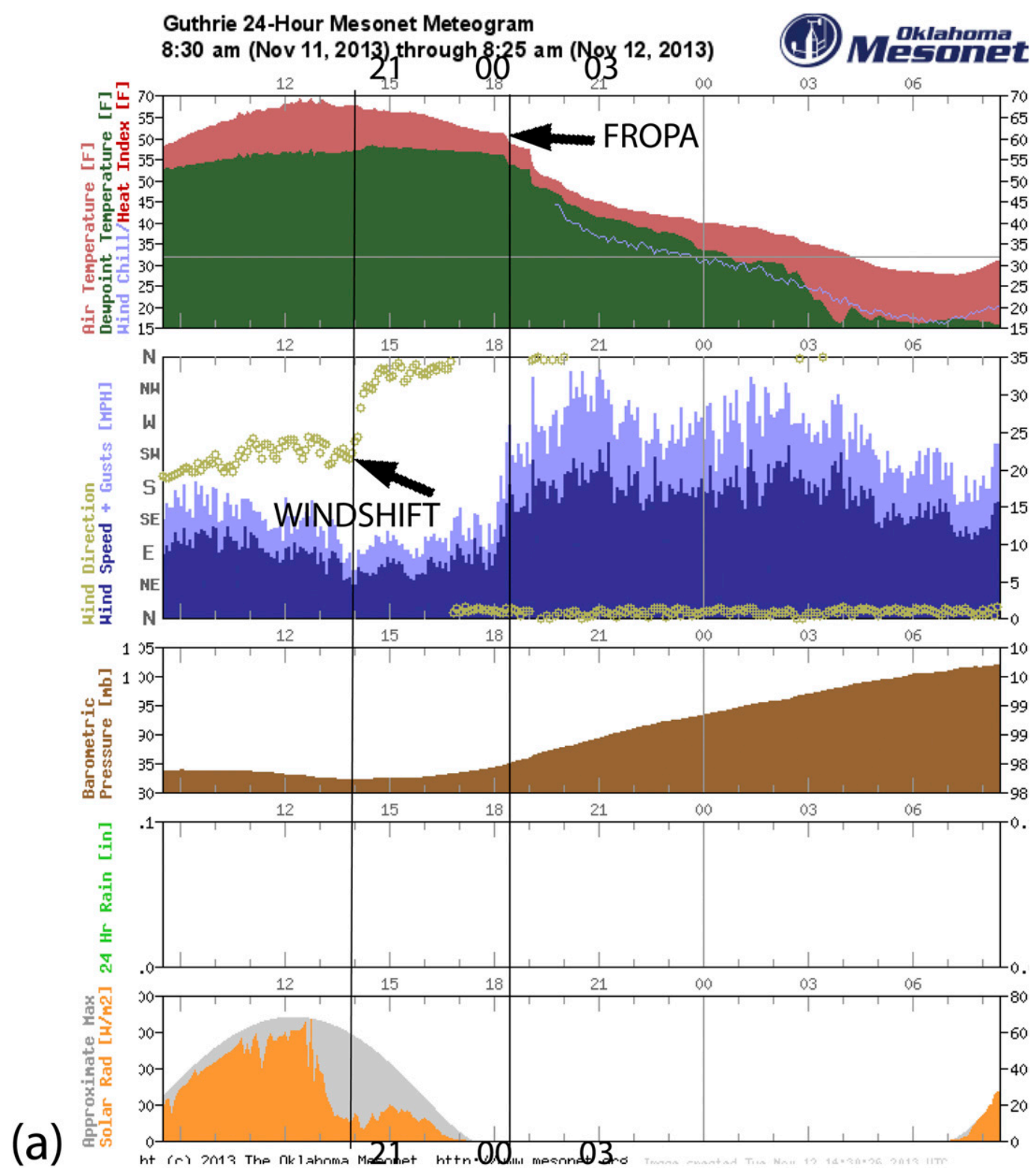

FIG. 3. Meteograms showing the passage of the prefrontal wind-shift line and cold front at (a) Guthrie, OK, and (b) Norman, OK. The frontal passage is indicated as "FROPA" and the prefrontal wind-shift line is indicated as "WINDSHIFT." Times are given in local time (small numbers), but UTC is also shown at 2100, 0000, and 0300 UTC. (from top to bottom) Temperature (pink) and dewpoint (green) $\left({ }^{\circ} \mathrm{F}\right.$ ), wind direction (small circles), and speed (blue; kt, or $\sim \mathrm{m} \mathrm{s}^{-1} \times 2$ ); station pressure (brown; hPa); rain (green; in.); and insolation (orange; $\mathrm{W} \mathrm{m}^{-2}$ ), where the maximum possible without clouds is given in gray.

gradient weaker; the surface ${ }^{3}$ wind speed was nearly calm for a short time period at Norman.

By late evening, the cold front had passed by all but far southeastern Oklahoma, where the pressure gradient

\footnotetext{
${ }^{3}$ When "surface" describes a characteristic of the wind based on the mesonet or the standard observing sites, it refers to anemometer level, usually $10 \mathrm{~m}$ AGL, not right at the surface.
}

was very weak and the surface winds were mostly calm (not shown). The PWL was therefore not discernible, except in far northwestern Texas. The cessation at night of vertical mixing due to heating and the onset of nocturnal radiational cooling likely were responsible for the weakening of the PWL.

\section{b. Radar analysis and finescale wind structure}

When the prefrontal wind-shift line passed through Norman, low-elevation scans (e.g., $0.5^{\circ}-1.5^{\circ}$ ) from the 


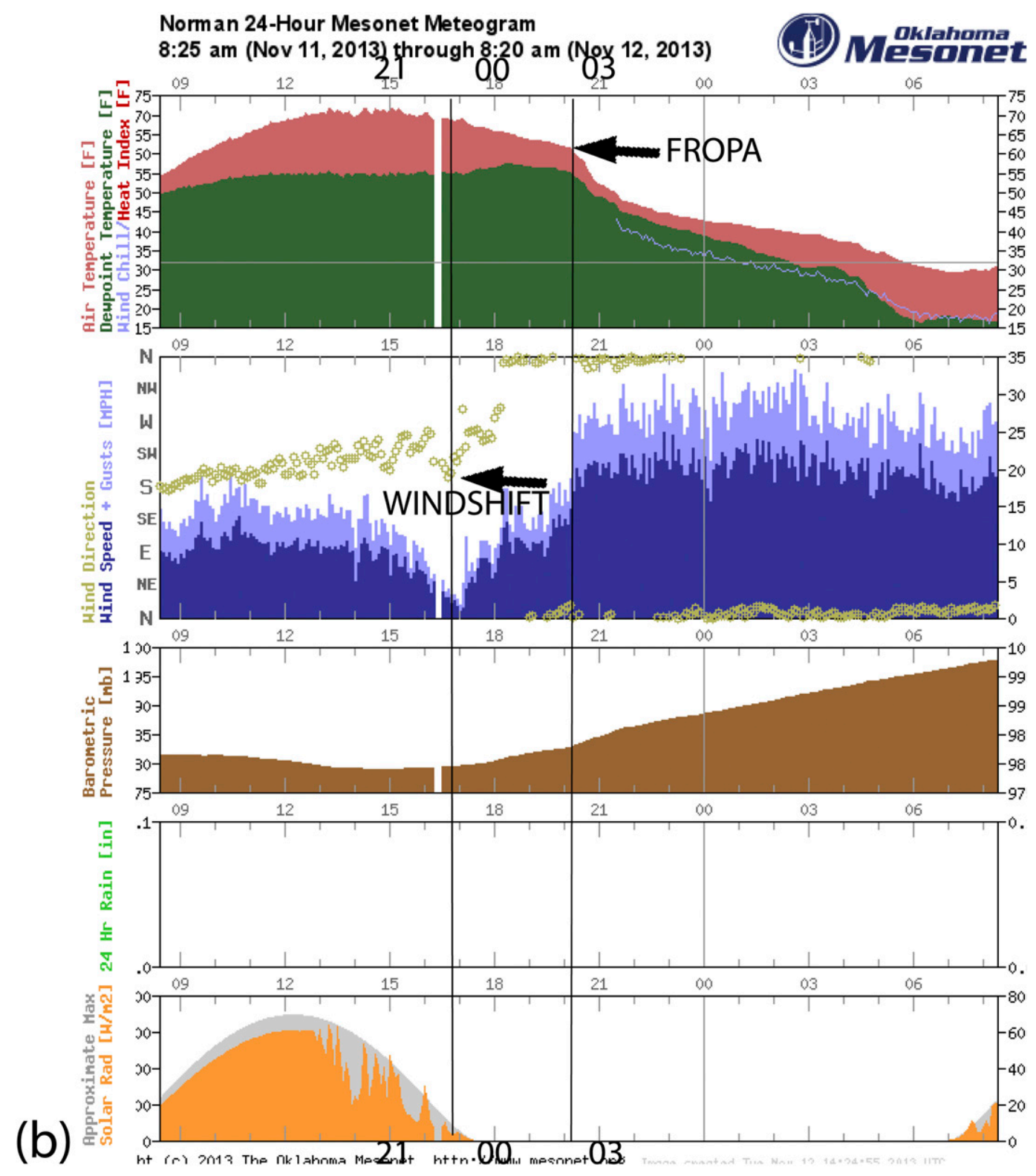

FIG. 3. (Continued)

WSR-88D near Oklahoma City (KTLX) indicated a lower-tropospheric ( $<1.0 \mathrm{~km}$ AGL) "fine line" of enhanced radar reflectivity ${ }^{4}\left(Z_{\mathrm{H}} \sim 15-25 \mathrm{dBZ}\right)$, with a northward-bending kink just south of the radar (Fig. 4). There is also a kink in the PWL to the northeast of the neutral point in the deformation field in an analysis of the wind field (not shown) based on mesonet data

\footnotetext{
${ }^{4}$ It is later shown from a dual-Doppler analysis that there was a band of convergence along the fine line.
}

(Fig. 2b), $2 \mathrm{~h}$ earlier and two counties $(\sim 40-50 \mathrm{~km})$ to the west. It is possible that the kink formed in response to a local maximum in southerly wind (e.g., at Minco, Oklahoma) and/or a local maximum in northerly wind to the west (e.g., at Ft. Cobb). The fine line propagated to the south (not shown) and was approximately coincident with a shift in the Doppler wind direction from south to north. It was also coincident with a band of enhanced differential reflectivity $\left(Z_{\mathrm{DR}}\right)$ exceeding $7 \mathrm{~dB}$-particularly along the leading edge of the fine line-and reduced copolar cross correlation coefficient $\left(\rho_{\mathrm{hv}}\right)$, below 

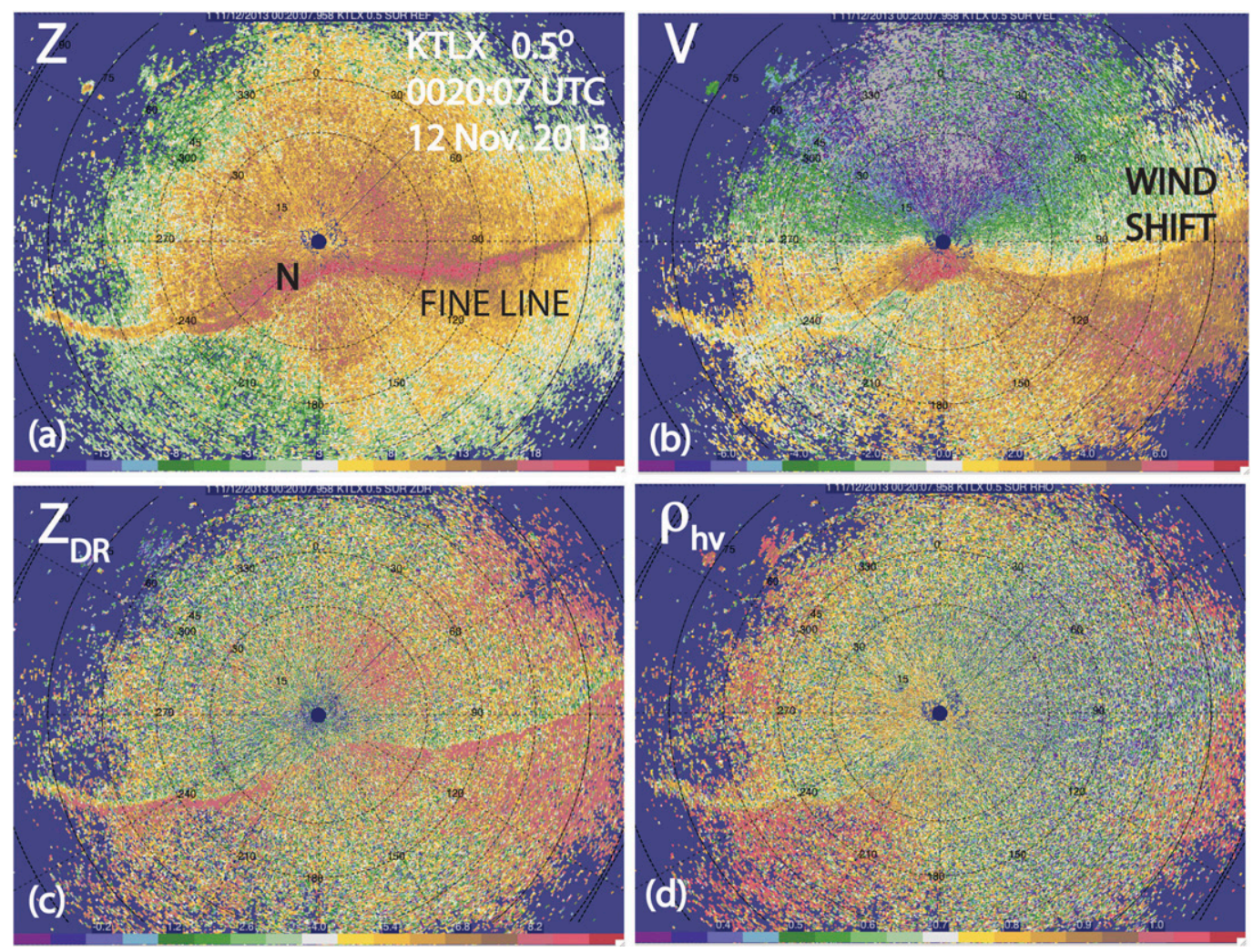

FIG. 4. KTLX WSR-88D at 0020:07 UTC 12 Nov 2013 at $0.5^{\circ}$ elevation angle (a) radar reflectivity $Z_{\mathrm{H}}(\mathrm{dBZ})$, (b) Doppler velocity $V\left(\mathrm{~m} \mathrm{~s}^{-1}\right)$, (c) differential reflectivity $\left(Z_{\mathrm{DR}} ; \mathrm{dB}\right)$, and (d) copolar cross-correlation coefficient $\left(\rho_{\text {hv }}\right)$, showing the prefrontal wind-shift line approximately the time it passed through Norman ("N"). Range markings are indicated every $15 \mathrm{~km}$.

0.7. Behind (i.e., north of) the fine line, $\rho_{\mathrm{hv}}$ remained depressed while $Z_{\mathrm{DR}}$ generally decreased, though with very high variance and "speckleness" (i.e., with much less reliability). The kink in the fine line and in the PWL probably represents the same wavelike feature, which propagated eastward along the PWL as it propagated southward. The kink propagated eastward no faster than $\sim 50 \mathrm{~km}(2 \mathrm{~h})^{-1}$, or $\sim 7 \mathrm{~m} \mathrm{~s}^{-1}$. If the wavelike feature were caused by horizontal-shear instability (e.g., Buban and Ziegler 2016), then the wave would be expected to propagate eastward at approximately the zonal wind speed averaged over both sides of the shear zone. The zonal component of the wind was zero north of the wind shift and no more than $\sim 3-7 \mathrm{~m} \mathrm{~s}^{-1}$ (Fig. 9, south of the PWL; Fig. 10, in the boundary layer). The wavelike feature must therefore have been caused by some process other than horizontal-shear instability.

A close-up, finer-scale radar analysis from KTLX is shown in Fig. 5 for the same time that the KTLX analyses are seen in Fig. 4. Narrow segments of multiple, parallel fine lines of enhanced reflectivity are evident just ahead of the main fine line. These fine lines are coincident with alternating lines of approaching (coded green) and receding (coded yellow) Doppler velocity. At low levels, these indicate alternating lines of convergence and divergence, and by continuity considerations, alternating bands of rising and sinking motion. Such features are characteristic of atmospheric bores (e.g., Coleman et al. 2009; Koch et al. 2008; Bluestein and Snyder 2015).

Although RaXPol operates at X band $(3-\mathrm{cm}$ wavelength) and KTLX operates at $S$ band $(10-\mathrm{cm}$ wavelength), a fine line of enhanced reflectivity is still evident in an even finer-scale analysis from RaXPol (Fig. 6), which is coincident with a shift in Doppler wind direction from southerly to northerly. Higher $Z_{\mathrm{DR}}$ and lower $\rho_{\mathrm{hv}}$ are still coincident with the fine line, though not everywhere along the line. It might be that at $\mathrm{X}$ band the polarimetric variables are more sensitive to variations in the scatterers being sampled along the wind-shift line (e.g., as would happen for non-Rayleigh-sized scatterers). It is thought that the scatterers responsible for the fine line are mainly insects, with a possible added contribution from some birds, in a few locations where 


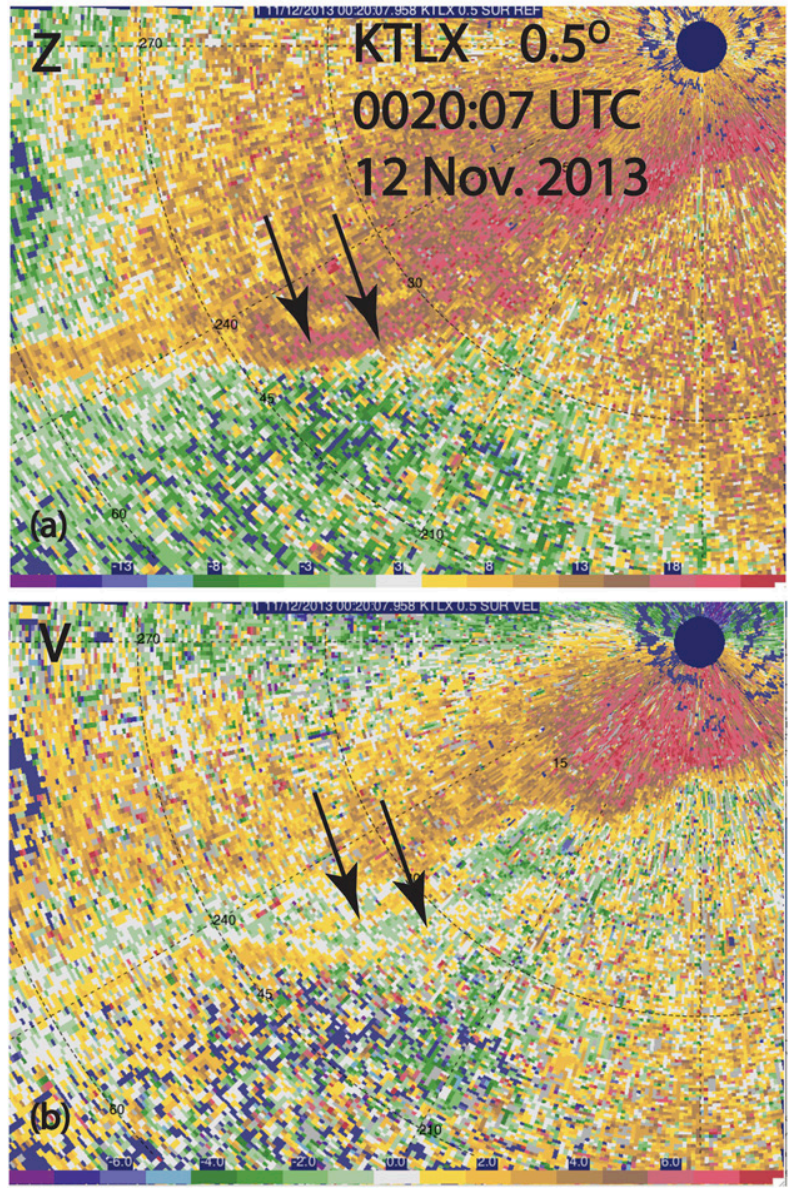

FIG. 5. As in Fig. 4, but an expanded view of just (a) radar reflectivity $Z_{\mathrm{H}}$ and (b) Doppler velocity $V$, of an area to the west of Norman, which shows evidence of bores. Arrows point to bands of enhanced reflectivity and a Doppler component away from the radar (yellow), with the approaching component (green) in between, probably associated with bores. Large black dot indicates the location of the radar.

the velocity data are significantly different from those of the surrounding area.

Range-height indicator (RHIs) scans from RaXPol approximately normal to the PWL were used to analyze vertical cross sections of radar variables across the PWL just before it had passed by the radar site (Fig. 7) in order to maximize the spatial resolution at the leading edge. Enhanced $Z_{\mathrm{H}}$ in clear air (no precipitation was noted at any of the mesonet stations when the PWL passed by) was greatest in a nose that was elevated $\sim 500 \mathrm{~m} \mathrm{AGL}$ and tapered down to the ground $\sim 2 \mathrm{~km}$ to the rear of the leading edge (Fig. 7a); drizzle was reported at Oklahoma City Will Rogers Airport ( $\sim 30 \mathrm{~km}$ northwest of Norman) at 0300 UTC (LST is $6 \mathrm{~h}$ earlier) and 0400 UTC, after passage of the front (not shown) and may have been responsible for some of the radar return later, but not just after the passage of the PWL. Corresponding noses of minima/maxima in $\rho_{\mathrm{hv}}$ and $Z_{\mathrm{DR}}$ are not evident (Figs. $7 \mathrm{c}, \mathrm{d}$ ), though reduced $\rho_{\text {hv }}$ (i.e., $<<1$ ) is noted at and several kilometers to the rear of the leading edge; there are two regions of reduced $Z_{\mathrm{DR}}$ at and several kilometers to the rear of the leading edge. The lowelevation angle polarimetric fields of both the S- and $\mathrm{X}$-band radars were consistent with insects or birds at the leading edge.

In the vertical cross section of Doppler velocity there is a jet of approaching wind, normal to the PWL, that is greatest about $500 \mathrm{~m}$ AGL, coincident with the leading edge of the nose of elevated reflectivity (Figs. 7a,b). This jet diminishes in intensity several kilometers to the rear of the leading edge; this change in intensity could be a result of a change in wind direction, but not speed, or an actual change in the speed of the jet (evidence for the former is presented in a subsequent section). In an animation (in the online supplement) the jet can be seen steadily progressing toward the radar at the same altitude.

After the PWL had passed by the RaXPol deployment site, analyses of RaXPol data continue to display multiple bands of enhanced radar reflectivity and oscillations in Doppler velocity on the southwestern portion of the leading edge of the prefrontal wind-shift line and enhancement of $Z_{\mathrm{DR}}$ along the leading edge of the fine line seen in $Z_{\mathrm{H}}$ (Fig. 8). These features are again consistent with bores and insects and/or birds. What are more evident in Fig. 8a than in Fig. 6a are approximately north-south-oriented bands of enhanced $Z_{\mathrm{H}}$ and $V$ to the rear of the fine line that marks the PWL. These features appear to be horizontal convective rolls (HCRs) (e.g., Weckwerth et al. 1997; Houser and Bluestein 2011) and could be organized by the vertical shear in the lowest $500 \mathrm{~m}$ consistent with the vertical profile of the component of the wind in approximately the northsouth direction seen in Fig. 7b.

The kinematic structure of the PWL and the surrounding boundary layer is revealed in a dual-Doppler analysis in the northwestern RaXPol-KTLX lobe (Fig. 9a). At $200 \mathrm{~m}$ AGL the PWL was marked by a $5-\mathrm{km}$-wide zone in which the wind behind the line veered from northwesterly to northerly (Fig. 9b). The curvature of the wind field in this zone was marked by a strip of cyclonic vorticity $\sim 2-4 \times 10^{-3} \mathrm{~s}^{-1}$, which fell within the fine line of reflectivity. The backing of the winds could explain why the jet apparent just behind the leading edge of the PWL decreased in intensity with distance to the rear of this feature (Fig. 7b), as the wind component became less perpendicular to the line. Ahead of the PWL the winds were weaker and generally varied from westerly to southwesterly. The convergence 


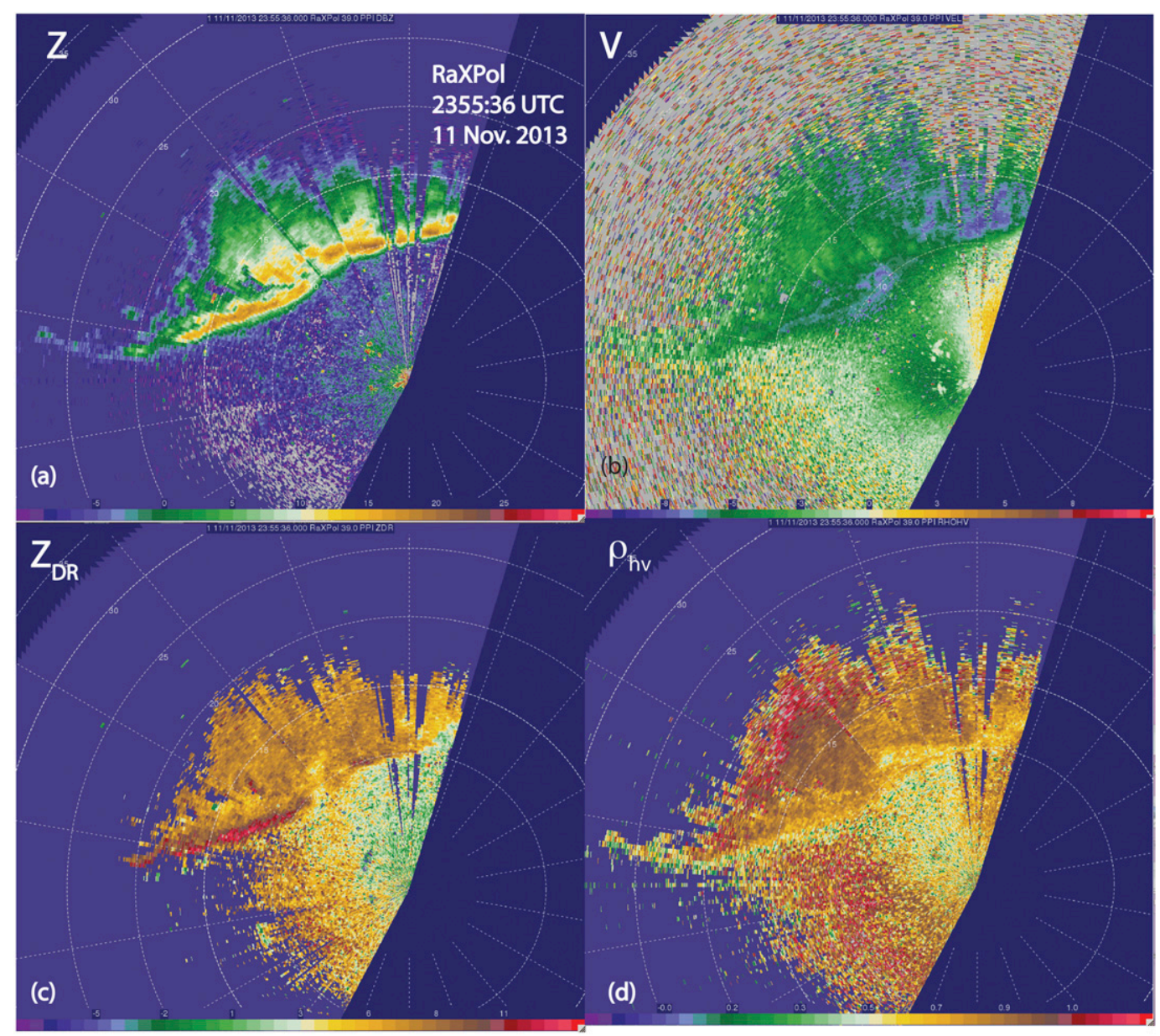

FIG. 6. RaXPol data at $\sim 2^{\circ}$ elevation angle at 2355:36 UTC 11 Nov 2013, before the prefrontal wind-shift line had passed by Norman. (a)-(d) As in Fig. 4. Range ring spacing is $5 \mathrm{~km}$.

at the leading edge of the PWL evident in the wind field (Fig. 9b) was associated with a strip of upward motion at $800 \mathrm{~m}$ AGL generally as strong as several meters per second in places (Fig. 9c). The transition of the winds from weak and approximately westerly to northwesterly and then northerly seen in Fig. 9b at $200 \mathrm{~m}$ AGL is also seen in the Guthrie meteogram at the surface (Fig. 3b); the Norman meteogram, however, does not actually show any wind measurements from the northwest. ${ }^{5}$

\footnotetext{
${ }^{5}$ If the prefrontal wind-shift zone is defined by the 5 -km-wide strip of cyclonic vorticity just behind the wind shift itself, then for a motion of $\sim 15 \mathrm{~m} \mathrm{~s}^{-1}$ (estimated from a sequence of mesonet observations; not shown), it takes $\sim 5$ min for the prefrontal wind-shift zone to pass by. Since the frequency of observations at mesonet sites is $5 \mathrm{~min}$, it is possible that an observation missed the short period of northwesterly winds. At some other sites, the period of northwest wind was observed (not shown).
}

\section{c. Finescale temperature structure}

Prior to the passage of the prefrontal wind-shift line, the sounding at Norman was characterized by a wellmixed boundary layer that extended from $925 \mathrm{hPa}$ up to $\sim 875 \mathrm{hPa}$ and a saturated, cloud layer above, extending up to $\sim 810 \mathrm{hPa}$ (Fig. 10a). Below $925 \mathrm{hPa}$ the boundary was well mixed with respect to potential temperature, but not moisture, perhaps owing to some horizontal advection of water vapor. Winds were $<5 \mathrm{~m} \mathrm{~s}^{-1}$ and from the west-southwest. Rapid drying occurred above the cloud layer and there was an inversion layer extending up to $\sim 710 \mathrm{hPa}$. In the inversion layer the wind speeds increased to $\sim 10-12.5 \mathrm{~m} \mathrm{~s}^{-1}$; this vertical structure is indicative of a north-south temperature gradient if the vertical shear can be associated with the thermal wind shear, and is probably associated with the remnants of a frontal zone that slopes upward to the north, the front having passed by at the surface 5-6 days earlier and having swept past the Texas Gulf Coast (not shown). 

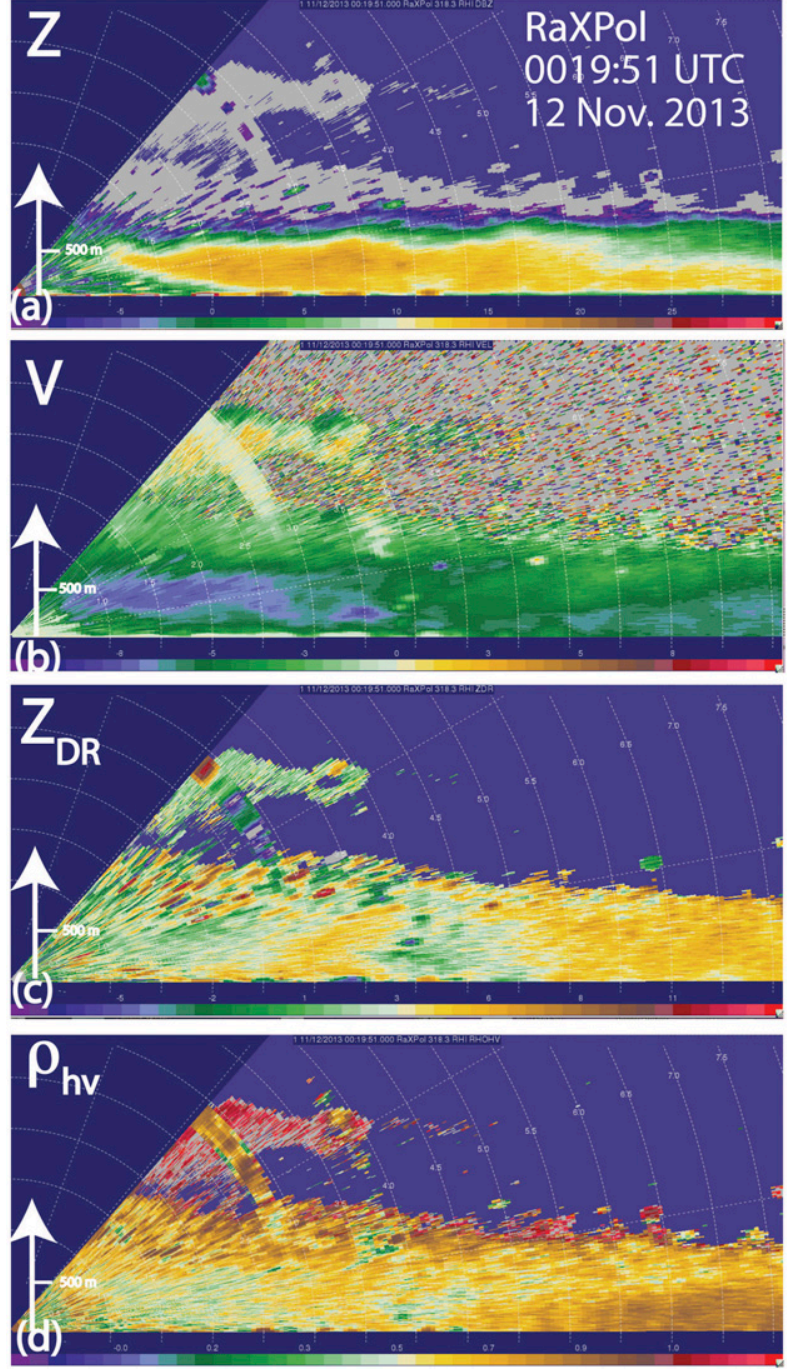

FIG. 7. Vertical cross sections at low levels through the leading edge of the prefrontal wind-shift line at 0019:51 UTC 12 Nov 2013 of (a) radar reflectivity factor $\left(Z_{\mathrm{H}} ; \mathrm{dB} Z\right)$, (b) Doppler velocity $\left(V ; \mathrm{m} \mathrm{s}^{-1}\right),(\mathrm{c})$ differential reflectivity $\left(Z_{\mathrm{DR}} ; \mathrm{dB}\right)$, and $(\mathrm{d})$ copolar cross-correlation coefficient $\left(\rho_{\mathrm{hv}}\right)$ from RHIs from RaXPol. Range ring spacing is $500 \mathrm{~m}$.

The passage of the PWL and the later passage of the cold front were evident in thermodynamic retrievals of the vertically pointing AERI, which serendipitously was operating while RaXPol was collecting data (Fig. 11). Prior to the passage of the PWL at $\sim 2300$ UTC and lasting until after the first northerly wind appeared, cloud-base height was about $1.3-1.5 \mathrm{~km}$ AGL. Data were not available when the winds first turned to northerly and ( $\sim 0010$ UTC; Fig. $3 b)$ because the instrument is always rebooted at $0000 \mathrm{UTC}$, or about $1.5 \mathrm{~h}$ later because the hatch for the instrument was closed at 0140 UTC owing to light precipitation.
After the first northerly wind at 0010 UTC, the temperature fell abruptly at $\sim 600 \mathrm{~m} \mathrm{AGL}$ at $\sim 0014$ UTC (coded as a transition from orange to yellow) by $\sim 2^{\circ} \mathrm{C}$, while about $10 \mathrm{~min}$ later at $\sim 0024$ UTC, the cloud ceiling dropped from $\sim 1.4 \mathrm{~km}$ AGL to $\sim 750 \mathrm{~m}$ AGL (Fig. 11). At 0040 UTC there was a simultaneous drop in temperature at $\sim 300 \mathrm{~m}$ (coded as a transition from red to orange) and a rise in temperature from $\sim 1.2$ to $\sim 1.8 \mathrm{~km}$ AGL (coded as a transition from green to light green). At the time the temperature dropped at $\sim 300 \mathrm{~m}$ AGL, the water vapor mixing ratio and dewpoint rose a few grams per kilogram and degrees Celsius, respectively, and the potential temperature dropped a few kelvin. The drops in temperature and increase in water vapor mixing ratio are greater than the uncertainties, which are $\sim 0.5^{\circ} \mathrm{C}$ and $0.5 \mathrm{~g} \mathrm{~kg}^{-1}$, respectively, at $\sim 300 \mathrm{~m}$ (not shown). So, the PWL occurred ( $\sim 2300$ UTC) in advance of the elevated temperature gradient ( $~ 0040$ UTC) by about $1.5 \mathrm{~h}$. The drop in the cloud-base height as measured by the ceilometer is consistent with an increase of parcel saturation point (SP) pressure (Betts 1984) related to the decrease in potential temperature and increase in water vapor mixing ratio after the passage of the PWL.

About the time the cold front passed by $\sim 0225$ UTC (Fig. 11a), the temperature from the surface up to cloud base $(\sim 750 \mathrm{~m})$ slowly began decreasing, as did the cloud-base height itself, while the temperature above $\sim 1.5 \mathrm{~km}$ AGL did not change. The frontal passage is seen most clearly in the time-height cross section of potential temperature, with a wedge of approaching, potentially cooler (blue) air below $1 \mathrm{~km}$ (Fig. 11c).

The aforementioned changes in thermal structure when the PWL passed are consistent with an elevated baroclinic zone that coincides with the portions of the enhanced reflectivity and the jet that were located near the bottom of the elevated baroclinic zone (cf. Figs. 11a and $7 \mathrm{~b}$ ). Such an elevated baroclinic zone and elevated jet are similar to a gravity current "intrusion" as described by Ungarish (2009), which propagates horizontally inside a stratified fluid rather than along a well-defined lower boundary (Fig. 12). The vertical structure of the environment into which the intrusion was moving (Fig. 10a) was well mixed above the surface near $975 \mathrm{hPa}$, but below $875 \mathrm{hPa}$, and saturated and statically stable from 875 up to $810 \mathrm{hPa}$. There was a strong inversion between 725 and $700 \mathrm{hPa}$.

Prior to the passage of the surface cold front and after cooler air was found aloft, the increase in temperature above $\sim 1.25 \mathrm{~km}$ was associated with an increase in static stability (warmer at $1.5 \mathrm{~km}$ AGL, cooler nearer to the surface) (Fig. 11a). The temperature did not decrease abruptly at the surface or up to $\sim 500 \mathrm{~m}$ AGL until about 

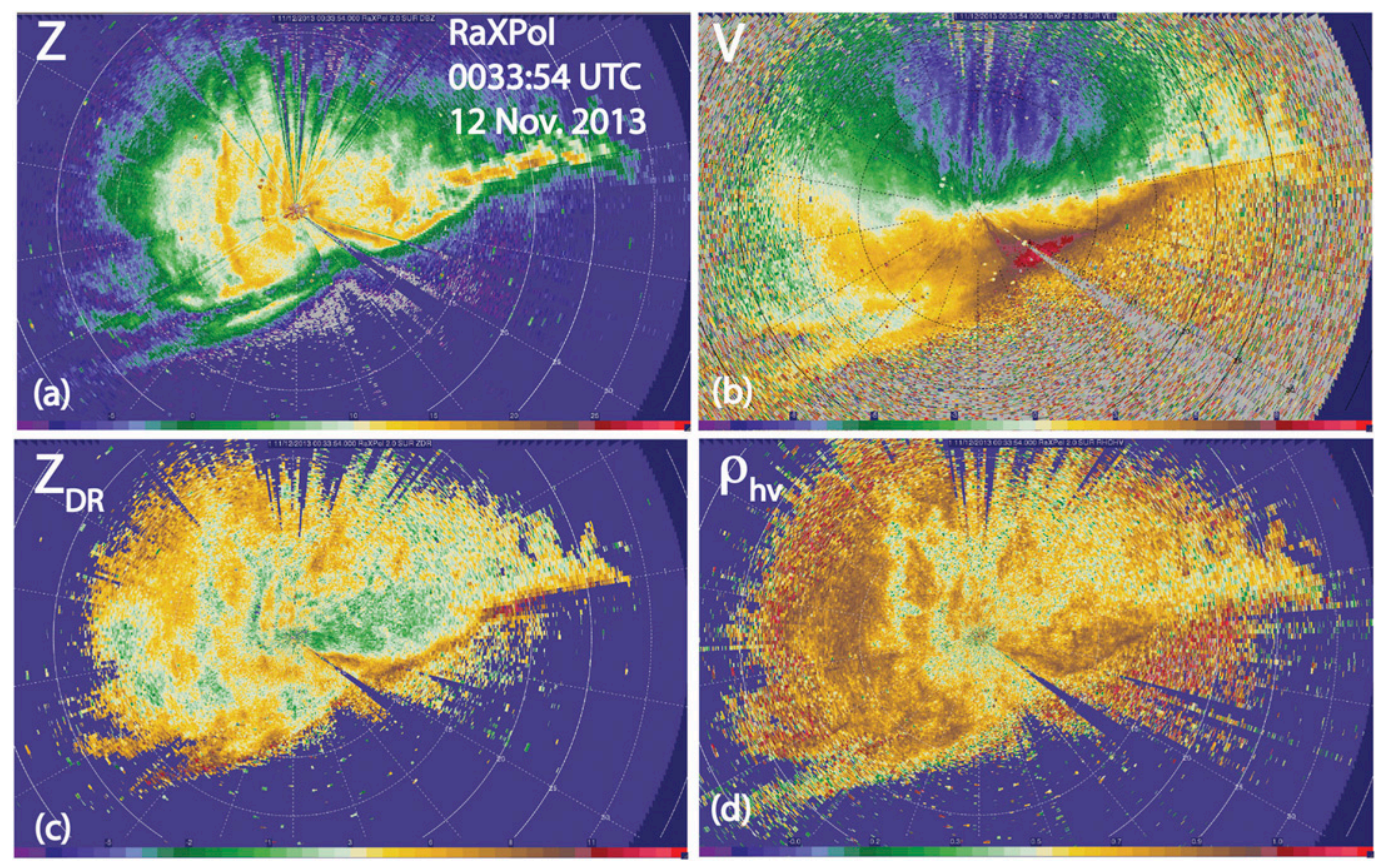

FIG. 8. As in Fig. 6, but after the prefrontal wind-shift line had passed, at 0033:54 UTC 12 Nov 2013.

30 min later, at $\sim 0220$ UTC. The surface front was therefore only $\sim 500 \mathrm{~m}$ deep when it passed and shallowest at the very leading edge. It is therefore hypothesized that the increase in temperature (and static stability) above $\sim 1 \mathrm{~km}$ may have been caused by the horizontal advection of warmer air aloft by the elevated jet ahead of the surface cold front. This interpretation must be accepted with extreme caution, however, because the accuracy of AERI temperature measurements above the cloud base to the rear of the leading edge of the prefrontal wind-shift line was only good to within $\sim 2^{\circ}-3^{\circ} \mathrm{C}$ (Fig. 11b) because the clouds are almost opaque to infrared radiance and thus the AERI has little sensitivity above the cloud base; on the other hand, the temperature uncertainty below the cloud base is relatively low. If the stable air above $\sim 1 \mathrm{~km}$ is real, then the waves in the fine line north of the PWL noted in the previous section may be caused by Kelvin-Helmholtz rolls, which require both shear and stable stratification (e.g., Houser and Bluestein 2011). Between 810 and $770 \mathrm{hPa}$, the lapse rate is dry adiabatic and nearly saturated (Fig. 10). Thus, the sounding is almost absolutely unstable. If it is indeed absolutely unstable, then turbulence could be generated in this layer.

The elevated jet could have also been responsible for triggering what appeared to be bores (Figs. 5 and 8) (Rottman and Simpson 1989; Klemp et al. 1997) ahead of the prefrontal wind-shift line as the intrusion encountered a layer of stable air. Koch and Clark (1999), for example, have documented a case in which a bore was triggered by a cold front intruding into an air mass having a nocturnal inversion. The subsequent discussion of bores is of interest in itself and probably does not affect the dynamics of the PWL significantly, though it could affect the surface temperature slightly. The Scorer parameter $l$ (Scorer 1949), where

$$
l^{2}=N^{2} / U^{2}-\left(d^{2} U / d z^{2} / U\right)
$$

and $N^{2}$ is the Brunt-Väisälä frequency and $U$ is the component of the relative wind normal to the prefrontal wind-shift line, was calculated from the Norman sounding just prior to the arrival of the prefrontal wind-shift line. A detailed analysis of all the necessary conditions for bore formation is beyond the scope of this study. It is noted though that in order for a bore to be long lived, it is important that upward-propagating gravity wave energy be trapped, which happens when $l$ decreases with height (Crook 1988). The Scorer parameter decreases with height when the stratification becomes less stable with height and/ or when the negative of the second vertical derivative of $U$ with height decreases with height, which can occur above a jet oriented approximately normal to the stable layer into which the elevated cooler air is intruding. Thus, ahead of a low-level stable layer and above an environmental layer of relatively higher static stability, $l$ may decrease with height.

In the Norman sounding ahead of the intrusion $l$ does decrease with height just below $700 \mathrm{hPa}$ (Fig. 10b) 
(a)
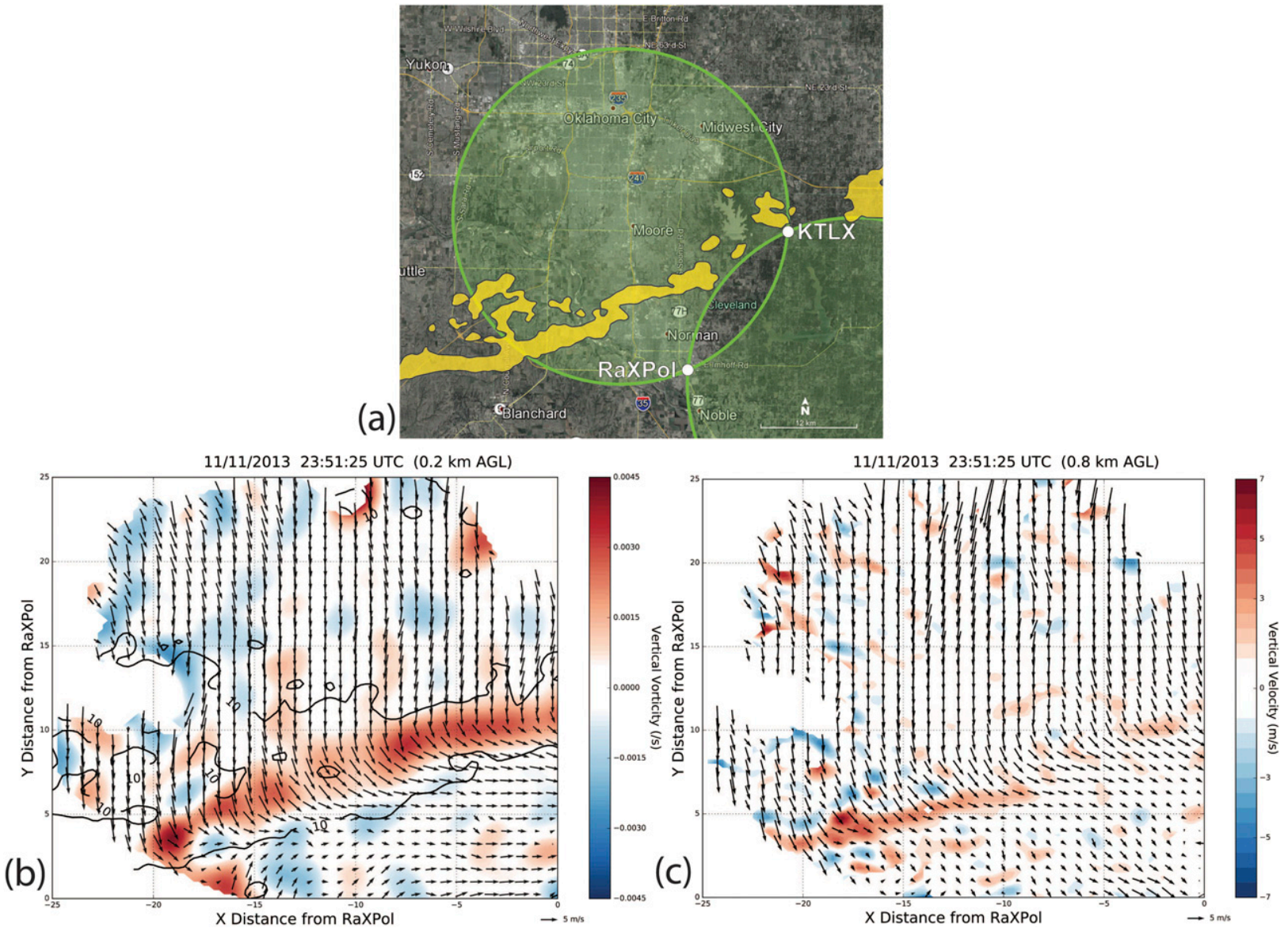

FIG. 9. (a) Dual-Doppler lobes (regions where the between beam angle is between $30^{\circ}$ and $150^{\circ}$, coded as transparent green) for RaXPol and KTLX. The 12-dBZ reflectivity contour from KTLX at the analysis time (2351:25 UTC 11 Nov 2013) is shaded in yellow; (b) dualDoppler analysis of the horizontal wind field at $200 \mathrm{~m}$ AGL, 10-dBZ contour of radar reflectivity from KTLX, and vertical vorticity (color scale); (c) as in (b), but at $800 \mathrm{~m} \mathrm{AGL,} \mathrm{and} \mathrm{vertical} \mathrm{velocity} \mathrm{(color} \mathrm{scale).}$

because there is a stable layer from $\sim 725$ to $700 \mathrm{hPa}$; vertical shear is relatively weak. This trapping layer is above the intrusion jet (by $\sim 2.5 \mathrm{~km}$ ) and no significant temperature falls were noted ahead of the prefrontal wind-shift line (Fig. 3b), which is consistent with the passage of a bore. However, a well-defined stable layer (or nocturnal inversion) was not found in the Norman sounding at the level of the intrusion before the prefrontal wind-shift line passed by, so it is difficult to explain how a bore could have been triggered in the first place; it is possible, however, that an hour or more after the sounding was released (e.g., at the times of Figs. 5b and 8) an evanescent wave had begun to develop (A. Shapiro 2016, personal communication). Significantly cooler surface temperatures were not noted though at nearby mesonet sites (not shown). It might have been that the waves detected were not bores at all, but rather Kelvin-Helmholtz waves (e.g., Houser and Bluestein 2011) or some other type of wave. A contrasting finescale analysis of a cold front without a PWL is now given.

\section{The cold front of 9 April 2013}

\section{a. Synoptic and mesoscale analysis}

During the afternoon of 9 April 2013 a strong surface cold front bisected Oklahoma along an arc from north-northeast to south-southwest (Fig. 13). Temperatures ranged from below freezing in the Oklahoma Panhandle to $29^{\circ} \mathrm{C}$ $\left(84^{\circ} \mathrm{F}\right)$ in southeastern Oklahoma. In southwestern Oklahoma the wind direction on opposing sides of the front differed by $\sim 180^{\circ}$, thus marking a line of strong low-level convergence. When it had become apparent, however, that severe convective storms rooted in the moist boundary layer ahead of the front were not going to form along the front, it was decided to collect mobile radar data when the front passed by the radar to 


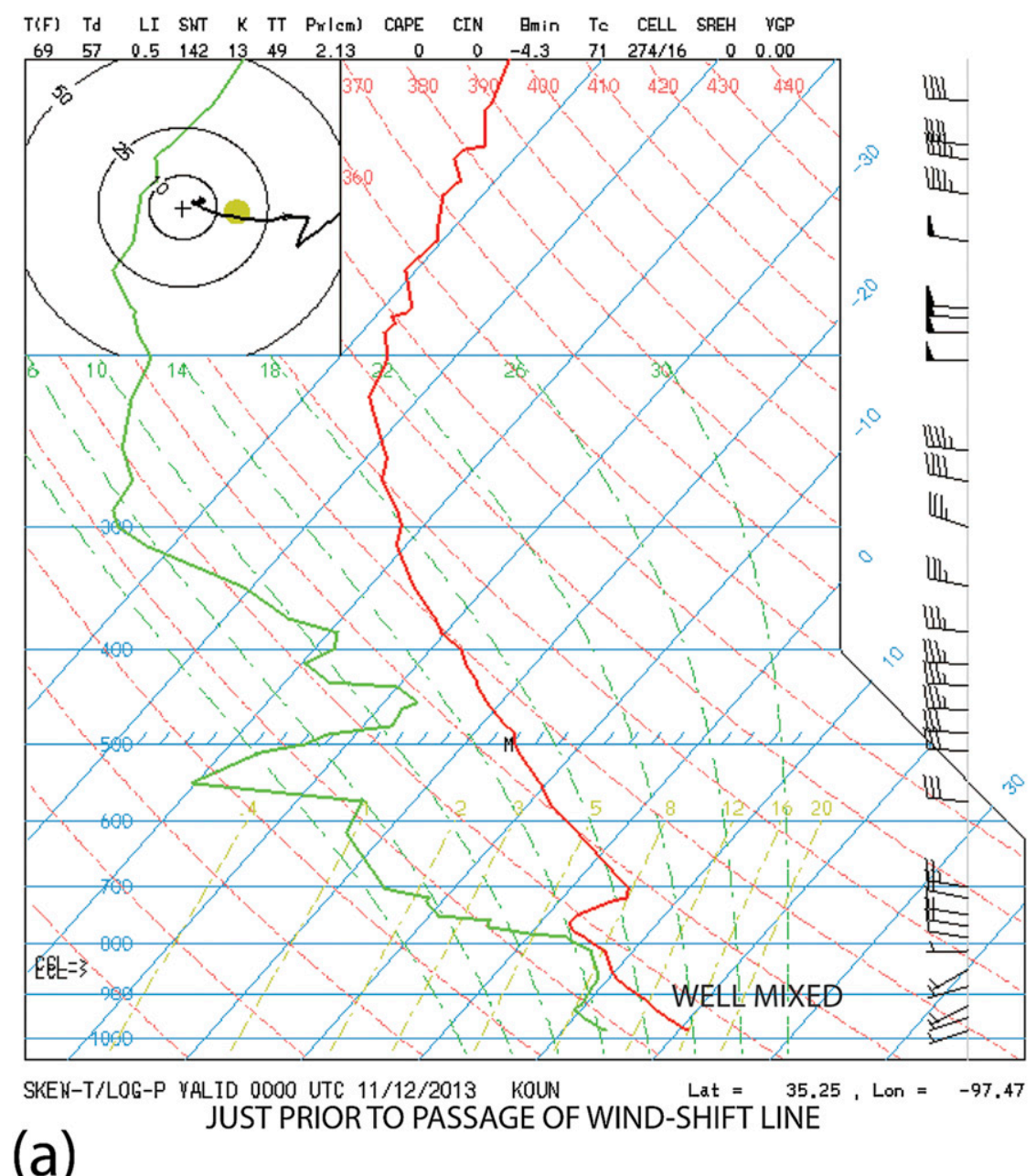

FIG. 10. (a) Sounding at Norman, OK, at 0000 UTC 12 Nov 2013, just before the passage of the prefrontal wind-shift line. Red line (green line) is the temperature (dewpoint) in ${ }^{\circ} \mathrm{C}\left({ }^{\circ} \mathrm{C}\right)$. Flags, whole wind barbs, and half wind barbs represent 25,5 , and $2.5 \mathrm{~m} \mathrm{~s}^{-1}$, respectively. (b) The square of the Scorer parameter as a function of pressure, computed from the sounding in (a) in $10^{-5} \mathrm{~m}^{-2}$. The "first term" (the static stability term; dashed red line) and the "second term" (the shear term; dashed blue line) of Eq. (2).

investigate as a target of opportunity the finescale structure of a strong cold front. This dataset allows us to compare the finescale vertical structure of the previously discussed PWL to that of a strong, classical cold front.

When the front passed by the mesonet site nearest to the RaXPol deployment site, which was at Apache, Oklahoma, $\sim 15 \mathrm{~km}$ to the west-southwest of $\mathrm{RaXPol},{ }^{6}$ the temperature (and dewpoint) fell off quasi exponentially with time and the wind shifted from the south-southeast

\footnotetext{
${ }^{6} 1.6 \mathrm{~km}$ north of Exit 62, the Cyril exit, at a rest area on the H. E. Bailey Turnpike. The location of the radar is denoted by "P" in Fig. A1.
}

immediately to the northwest and later to the north, while wind gusts increased in speed (Fig. 14). Frontal passage marked a trough of low pressure and the station pressure rose steadily for several hours following frontal passage (at a rate of $\sim 0.75-1.0 \mathrm{hPah}^{-1}$ ). Thus, this cold front had the characteristics of a classical cold front.

The leading edge of the cold front was marked by a line of clouds (Fig. 15), which on the cold side of the front had parallel, small-scale bands of clouds oriented approximately normal to the front in a mesoscale swath that extended from the Texas border to the southwest to almost as far as the Kansas border to the north-northeast (Fig. 16). 


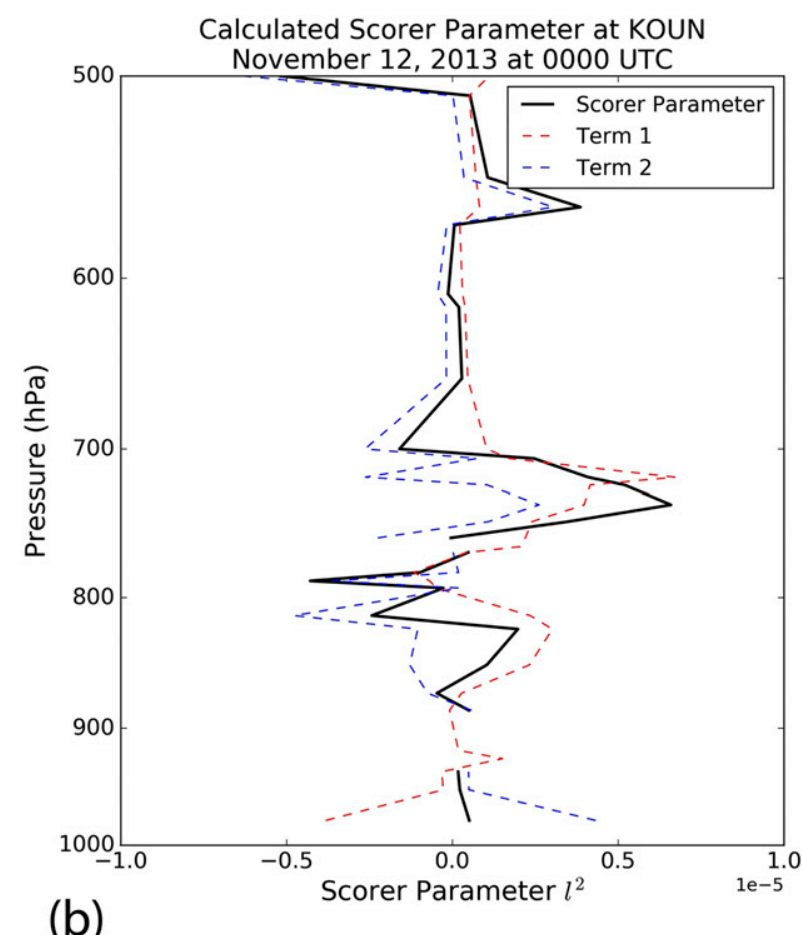

FIG. 10. (Continued)

\section{b. Radar analysis and finescale wind structure}

RaXPol resolved segments of bands of enhanced clear-air $Z_{\mathrm{H}}$ prior to the passage of the cold front, which were oriented in the north-northwest to south-southeast wind direction (Fig. 17a). These bands were probably caused by small insects caught up in the mesoscale updrafts (e.g., Ziegler et al. 2007). In an animation (see the online supplement), reflectivity elements are seen propagating along the bands to the north-northwest. Although it is difficult to discern any corresponding features in $V$ (Fig. 17b), perhaps because the banded structures were so segmented, there were some banded structures evident, but they appeared to be of a finer spatial scale than that of the bands of enhanced $Z_{\mathrm{H}}$ (Fig. 17a). The quasi-linear bands in $Z$ had the appearance of HCRs (e.g., Weckwerth et al. 1997). The segmented character of the bands may be a result of destructive interference between longitudinal and transverse rolls in the convective boundary layer ahead of the front (Ziegler et al. 2007).

At $\sim 2116$ UTC (not shown), a fine line located along the leading edge of the front appeared within the $15-\mathrm{km}$ range and approached the radar site; to the rear of the front no bands were discernible (Fig. 17a, shortly thereafter at 2122 UTC). As the front propagated away, the fine line along its leading edge comprised separate bulges or arcs (Fig. 18a). Similar arclike or "cleft" and "lobe" structures are found at the head of density currents, owing to gravitational instability when the denser fluid behind the density current overruns the ambient, less-dense fluid underneath (Simpson 1982). Stonitsch and Markowski (2007, see their Fig. 16) also documented arclike, bulging structures in nonprecipitating fronts, although they postulated that these are caused by horizontal shear instability across the front.

Some evidence of HCRs on the warm side of the front was still found. Some structures oriented nearly normal to the front are seen in both reflectivity and Doppler velocity (Fig. 18). To the rear of the front, elevated convective storms appeared, some of which had originated far to the southwest (Fig. 16), out of range of the radar, while others appeared to form $\sim 15$ $20 \mathrm{~km}$ to the rear of the leading edge of the front (not shown).

Vertical cross sections through the front were available from RHIs approximately normal to the front (Fig. 19) when the front was within $\sim 15 \mathrm{~km}$ of the radar. In an animation (see the online supplement) a nose of enhanced $Z_{\mathrm{H}}$ associated with the fine line of $\sim 2 \mathrm{~km}$ in width extending up to $\sim 400 \mathrm{~m}$ AGL can be seen passing by. A wedge of approaching Doppler velocities is seen coincident with the fine line, which extends up to $\sim 400-500 \mathrm{~m}$ AGL. What look like Kelvin-Helmholtz rolls (in $Z_{\mathrm{H}}$ ) are seen, in the animation (see the online supplement), being shed to the rear of the leading edge of the front. A core of the strongest approaching velocities (coded blue) are found $\sim 1 \mathrm{~km}$ behind the leading edge near and just above the ground (Fig. 19b). The top of the interface $\left(V=0 \mathrm{~m} \mathrm{~s}^{-1}\right.$, coded white) between approaching (below) and receding (above) $V$ is consistent with waves having a horizontal wavelength of $\sim 1 \mathrm{~km}$.

\section{Discussion and conclusions}

\section{a. Comparison of the 9 April 2013 cold front with the prefrontal wind-shift line of 11 November}

Since only one case with a PWL and one case with a more classical cold front without a PWL are presented, it is not possible to generalize with high confidence what the differences in finescale structure are between the generic PWL and the classical cold front. More studies such as these from serendipitous data collection and from field programs (e.g., Ziegler et al. 2007) are needed. If the cases discussed are indeed representative, then the PWLs appear to be intrusions, with elevated jets, while intense classical cold fronts appear to be like density currents, with jets nearer to the surface, 


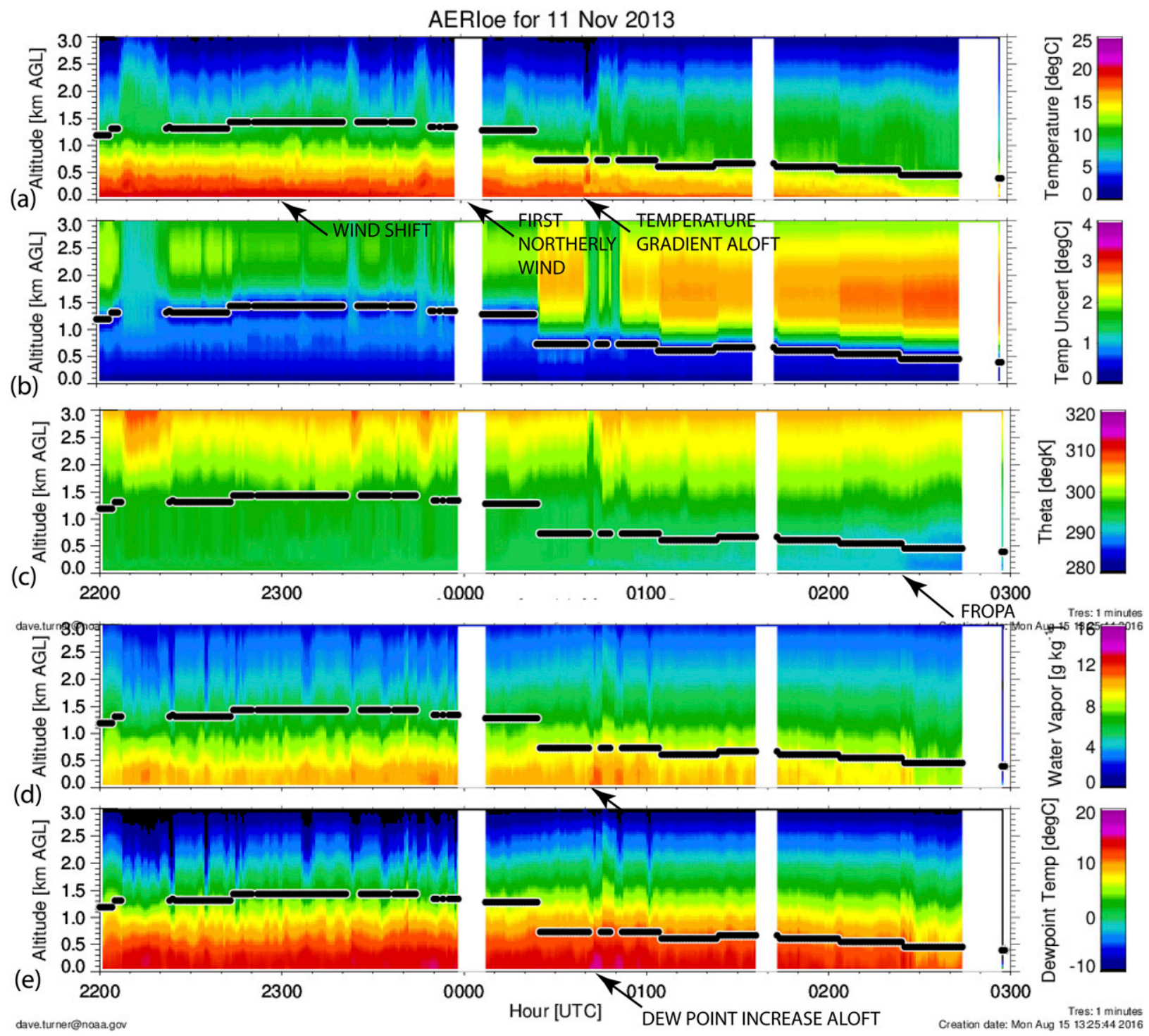

FIG. 11. (a) Retrieved temperature $\left({ }^{\circ} \mathrm{C}\right)$, (b) temperature uncertainty $\left({ }^{\circ} \mathrm{C}\right)$, (c) potential temperature $(\mathrm{K})$, (d) water vapor mixing ratio $\left(\mathrm{g} \mathrm{kg}^{-1}\right)$, and (e) dewpoint $\left({ }^{\circ} \mathrm{C}\right)$ from AERI, from 2200 UTC 11 Nov to 0300 UTC 12 Nov 2013 as a function of time (abscissa) and height (ordinate; 30-35 m must be added to yield the true altitude AGL). Refer to Fig. 3b to correlate the beginning of the wind shift at $\sim 2300$ UTC, the first northerly wind at $\sim 0000$ UTC, and the passage of the surface cold front (FROPA) at $\sim 0225$ UTC, with the behavior of the retrieved temperature in this figure.

coincident with the drop in surface temperature, and exhibiting a wedge-like leading edge.

Though dual-Doppler analyses were not available for the strong cold front case, the turning of the winds behind the wind-shift line are characteristic of classical frontal structure (e.g., Bluestein 1993), in that there is both cyclonic vorticity and convergence along the leading edge. It is hoped that in the future mobile profilers can be used in conjunction with mobile Doppler radar data to map out the finescale structure of both the kinematic and thermodynamic structures of strong classical cold fronts.

\section{b. Dynamics of the prefrontal wind-shift line}

We now speculate why characteristics of the PWL and of the trailing cold front differ. Both the PWL and the trailing cold front are what Cohen and Schultz (2005) refer to as "airstream boundaries" because airstreams having different origins are brought together. In the case of the former, there is an abrupt change in wind direction, but unlike 


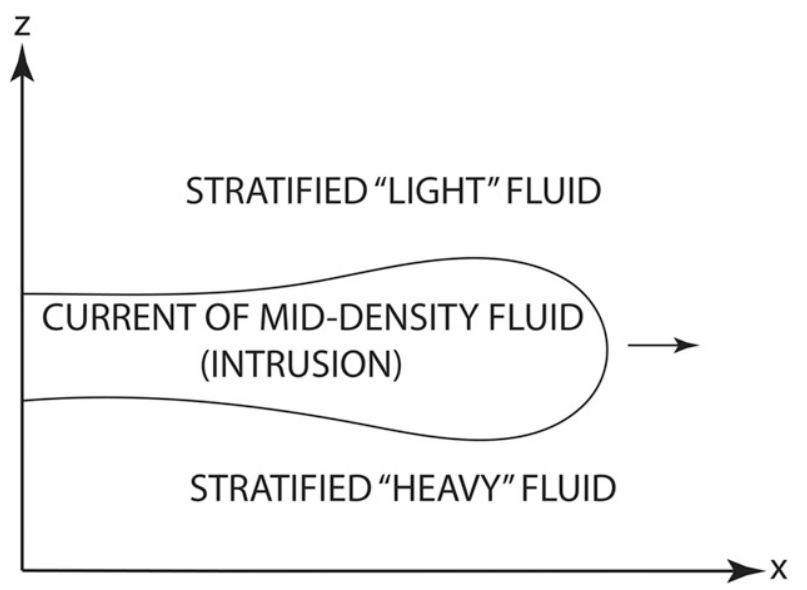

FIG. 12. Idealized depiction of an "intrusion" propagating horizontally inside a stratified fluid, not on a well-defined lower boundary. [After Ungarish (2009), see his Fig. 1.1.]

fronts, little or no change in temperature; in the case of the latter, there is an abrupt change in wind speed and temperature, but unlike classical fronts, little or no change in wind direction. The wind field along the cold front is characterized mainly by convergence while the wind field along the PWL is partly characterized by deformation and partly by convergence. Schultz (2004) found that the "timing and location of cyclogenesis was responsible for" the differences in the structure of PWLs and classical cold fronts and that diagnoses of the frontogenesis function can be used to assess the behavior of the front and prefrontal wind-shift line. In our case, focusing only on the finescale aspects of the PWL, we find that the wind speeds normal to the cold front were stronger on the cold side of the (trailing) cold front than they were in the zone between the cold front and the PWL (Figs. $2 b$ and 9). Furthermore, there was little or no change in wind direction across the trailing cold front (Fig. 2b). It therefore must be that air parcels approaching the trailing cold front from the cold side do not reside long enough in the convergence zone, where the wind speeds decrease downstream with little change in direction, for convergence acting on Earth's vorticity to increase the surface vorticity significantly.

On the other hand, air parcels approaching the PWL from the cooler side may spend more time in the convergence zone because the parcels turn somewhat as they approach the axis of dilatation of the wind field (to the left to the northeast of the neutral point and to the right to the southwest of the neutral point). These deformed air parcels thus have a component or motion along the wind-shift line, which can result in the production of vorticity by convergence acting on Earth's and any existing relative vorticity along the convergence zone

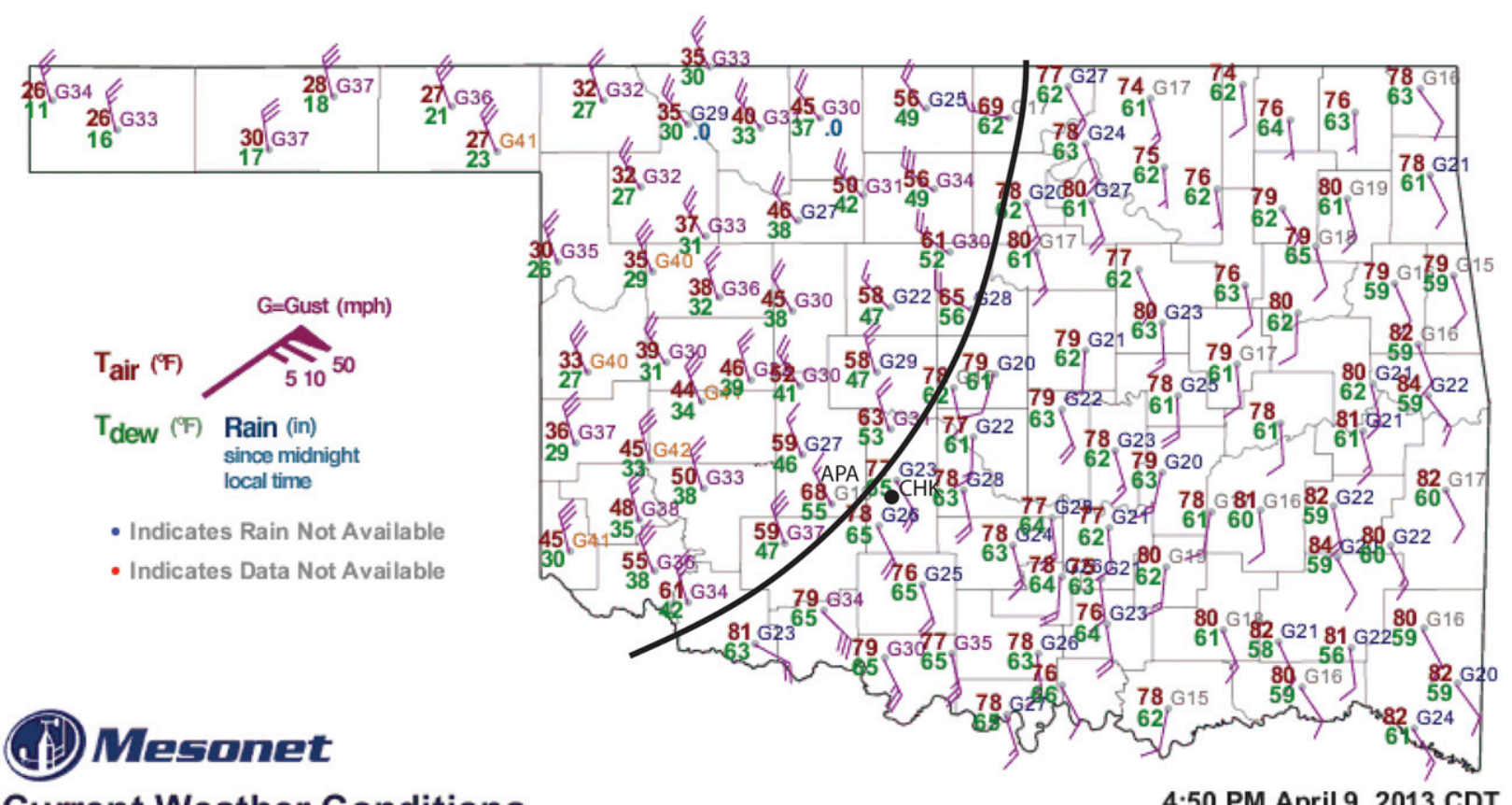

\section{Current Weather Conditions}

FIG. 13. Surface observations with the cold front indicated (solid black line), from the Oklahoma Mesonet, at 2150 UTC (1650 CDT) 9 Apr 2013. The black dot indicates the location of RaXPol; sites at Apache (APA) and Chickasha (CHK) are noted. Temperature and dewpoint are plotted in ${ }^{\circ} \mathrm{F}$; whole wind barbs $=5 \mathrm{~m} \mathrm{~s}^{-1}$, and half wind barbs $=2.5 \mathrm{~m} \mathrm{~s}^{-1}$. 


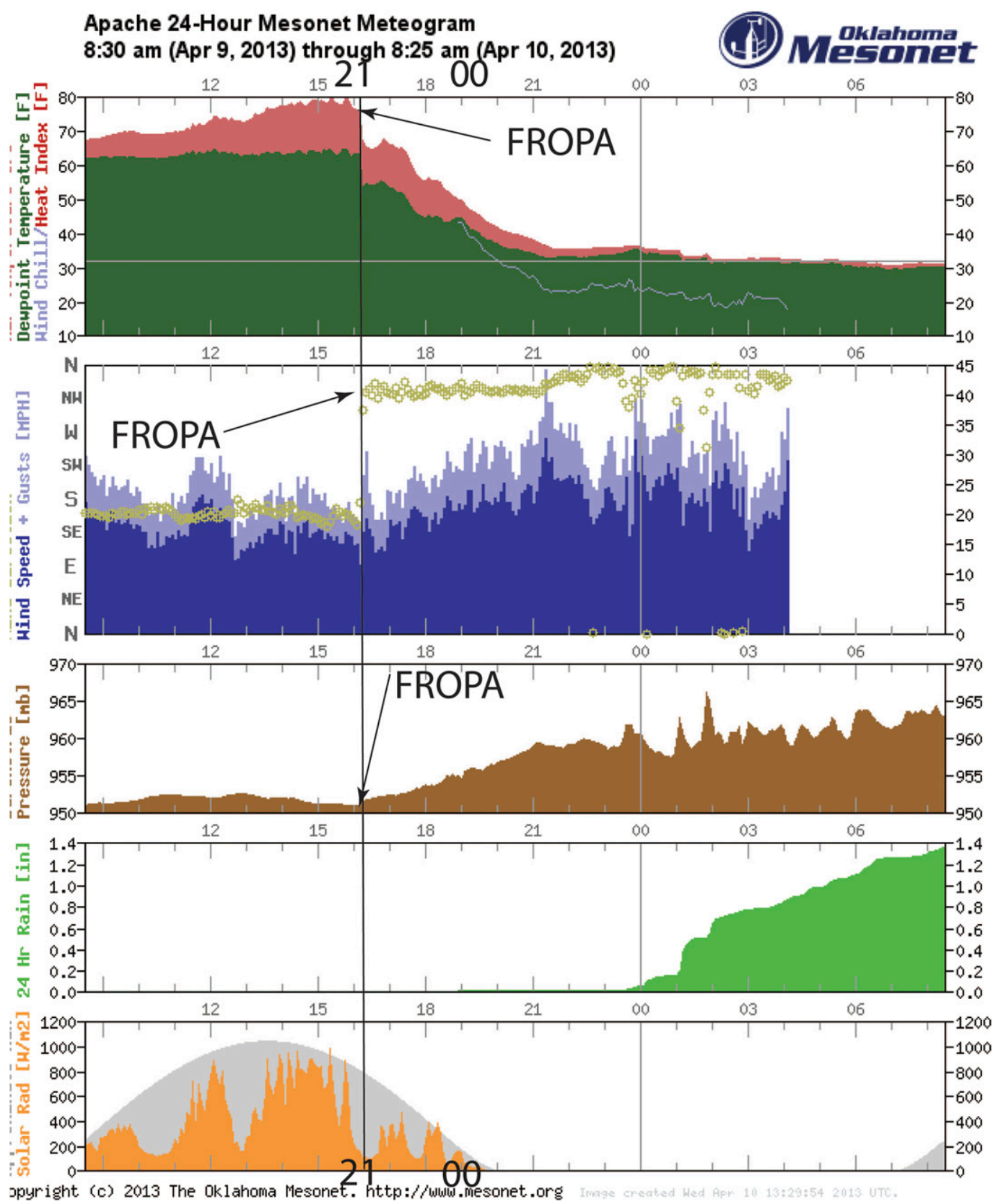

FIG. 14. Meteogram at Apache, OK, showing the well-defined passage of the cold front ("FROPA") at 2210 UTC 9 Apr 2013. Times plotted in UTC (at " 0 " and " 21 "); otherwise in CDT (small numbers). Units are given as in Fig. 3.

for a longer period of time. It is not known how much the effect of vertical excursions has on the time spent in the convergence zone because dual-Doppler analyses were relatively shallow and not available for the trailing front.

Since our explanation of why vertical vorticity is present along the PWL but not along the trailing front is qualitative because detailed, gridded three-dimensional wind data are not available for both the PWL and the trailing cold front, it is suggested that high-resolution numerical simulations be used to investigate the dynamics of the PWL and to test our proposed hypothesis.

Acknowledgments. This study was supported by NSF Grant AGS-1262048. RaXPol was built with MRI grant from NSF (Grant AGS-0821231). RaXPol is supported 

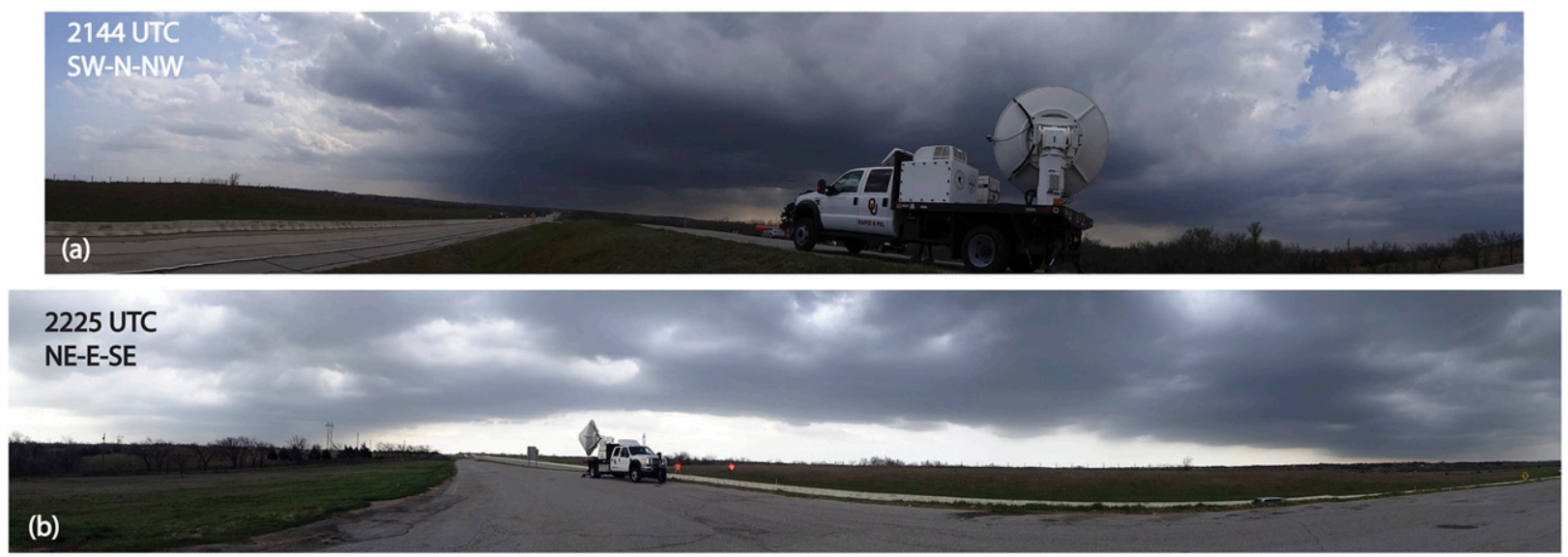

FIG. 15. Panoramic photographs of the clouds seen before the frontal passage, at 2144 UTC 9 Apr 2013, from the southwest (left) to the west to the northwest (right); and after the frontal passage, at 2225 UTC 9 Apr 2013, from the northeast (left) to the east to the eastsoutheast (right). RaXPol is seen in both images. The location of the radar is denoted by "P"' in Fig. 20. (Courtesy of H. Bluestein.)

by the Advanced Radar Research Center (ARRC) at the University of Oklahoma (OU). We are indebted to John Meier, Tian Yu, and Bob Palmer at the ARRC for their radar support. Funding for JCS was provided by NOAA/Office of Oceanic and Atmospheric Research under NOAA-University of Oklahoma Cooperative Agreement NA11OAR430072, U.S. Dept. of Commerce. We are also grateful for the insight of Rich Rotunno (NCAR), Kevin Haghi (OU), and Alan Shapiro (OU), and the assistance of Vivek Mahale (OU) on data collection on 9 April 2013. Part of this research was done while the first author was on sabbatical leave in the Mesoscale and Microscale Meteorology Division at NCAR. $\mathrm{He}$ is also indebted to NCAR for being awarded an NCAR Faculty Fellowship. Three anonymous reviewers and the editor, Todd Lane, provided constructive comments.

\section{APPENDIX A}

\section{A Map of Selected Locations in Oklahoma}

A map of locations mentioned in the text is shown in Fig. A1 so that readers not familiar with Oklahoma geography can more easily interpret the data displays and analyses.

\section{APPENDIX B}

\section{Polarimetric Analysis of the Fine Line in the PWL}

We note, for historical reference, that in the first radar study of a nonprecipitating front (which made use of a radar without polarimetric capabilities), it was thought that the fine line was caused by index-ofrefraction gradients (Ligda and Bigler 1958) such as in Bragg scattering. Isotropic Bragg scattering, however, should be associated with $Z_{\mathrm{DR}} \sim 0 \mathrm{~dB}$ (e.g., Melnikov et al. 2011) and backscatter differential phase $\delta \sim 0^{\circ}$ (implied by total measured differential phase $\Phi_{\mathrm{DP}}$ equaling the system differential phase $\Phi_{\text {sys }}$ in the absence of attenuation), which is not observed here (not shown). When data from radars operating at two different wavelengths are compared, the difference in the equivalent radar reflectivity factor at the two wavelengths owing to Bragg scattering $\left(\Delta Z_{\text {Bragg }}\right)$ is (e.g., Knight and Miller 1993)

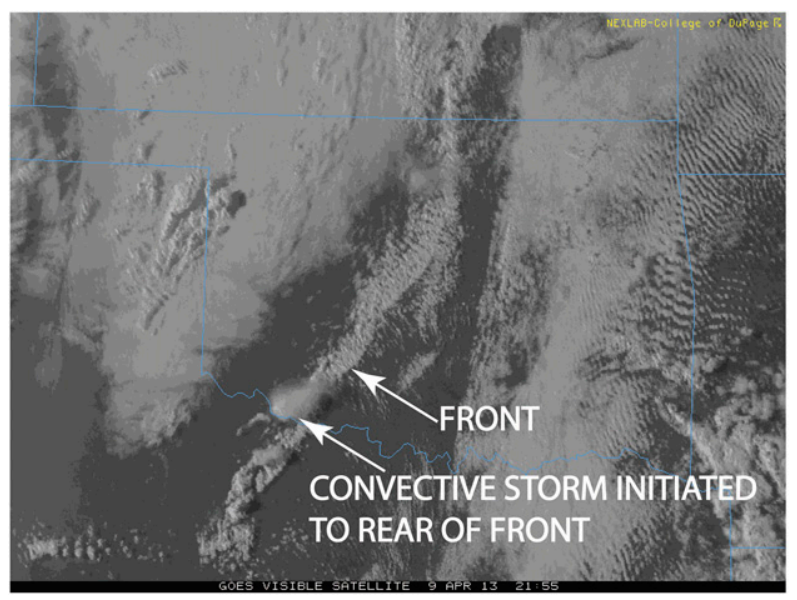

FIG. 16. Visible GOES satellite image over portions of the southern plains at 2155 UTC 9 Apr 2013, in which a line of clouds appear along the leading edge of and to the rear of the front. The anvil from a convective storm initiated to the rear of the front is noted. 

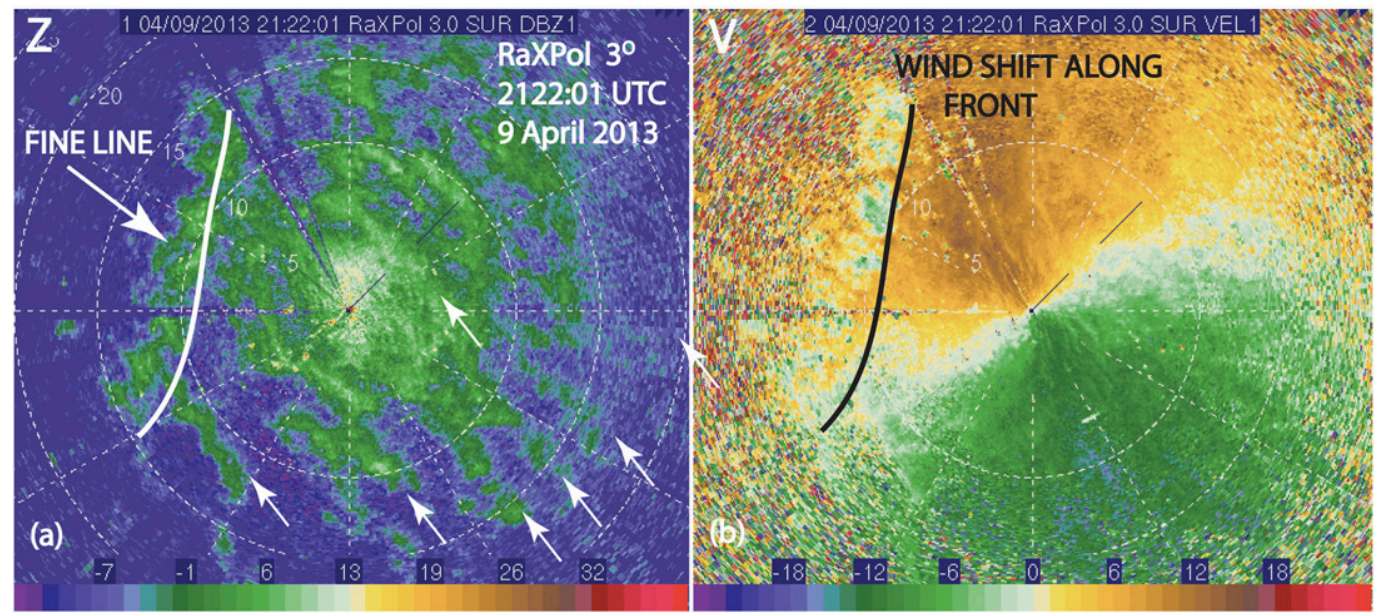

FIG. 17. Approach of a strong cold front as depicted by RaXPol (a) radar reflectivity factor $\left(Z_{\mathrm{H}} ; \mathrm{dB} Z\right)$ and (b) Doppler velocity $\left(V ; \mathrm{m} \mathrm{s}^{-1}\right)$, at 2122:01 UTC 9 Apr 2013, at $3^{\circ}$ elevation angle. In (a), a fine line is seen just to the rear of the wind-shift line (white) and arrows point to selected fine lines probably associated with horizontal convective rolls in the boundary layer. In (b), the wind shift at the front is marked by a black line. Range rings are marked every $5 \mathrm{~km}$.

$$
\Delta Z_{\mathrm{Bragg}}=Z_{\mathrm{H} 1}-Z_{\mathrm{H} 2}=10 \log _{10}\left[\left(\lambda_{1} / \lambda_{2}\right)^{11 / 3}\right],
$$

where $Z_{\mathrm{H} 1}$ and $Z_{\mathrm{H} 2}$ is the equivalent $Z_{\mathrm{H}}$ at wavelengths $\lambda_{1}$ and $\lambda_{2}$, respectively. Using KTLX's $\lambda \sim 10 \mathrm{~cm}$ and RaXPol's $\lambda \sim 3 \mathrm{~cm}, \Delta Z_{\text {Bragg }}$ from these two radars should be near $20 \mathrm{~dB} Z$. However, in this particular case, the difference in the reflectivity factor between RaXPol and KTLX is quite small; not only is the difference in reflectivity factor between the radars quite small, both KTLX and RaXPol show maximum $Z_{\mathrm{H}}$ of $\sim 20$ $25 \mathrm{dBZ}$ along the radar fine line, which would be very high for Bragg scattering (e.g., Ralph 1995). This observation, when combined with the observed distribution of polarimetric quantities (e.g., $Z_{\mathrm{DR}}$ in excess of $7 \mathrm{~dB}, \rho_{\mathrm{hv}}$ of $0.3-0.7$, and very high $\delta$ of $50^{\circ}$ to more than $100^{\circ}$ ) and the high variance in all radar fields support the notion that the scattering within the radar fine line is primarily from biological sources such as insects and birds (e.g., Wilson and Schreiber 1986; Wilson et al. 1994; Zrnić and Ryzhkov 1998, 1999; Martin and Shapiro 2007) and not so much from Bragg scattering, which is associated with generally lower $Z_{\mathrm{H}}, \delta \sim 0^{\circ}, Z_{\mathrm{DR}} \sim 0 \mathrm{~dB}$, and $\rho_{\mathrm{hv}}>0.99$ (e.g., Melnikov et al. 2011). This interpretation is complicated by the azimuthal variability of the mean values observed in the
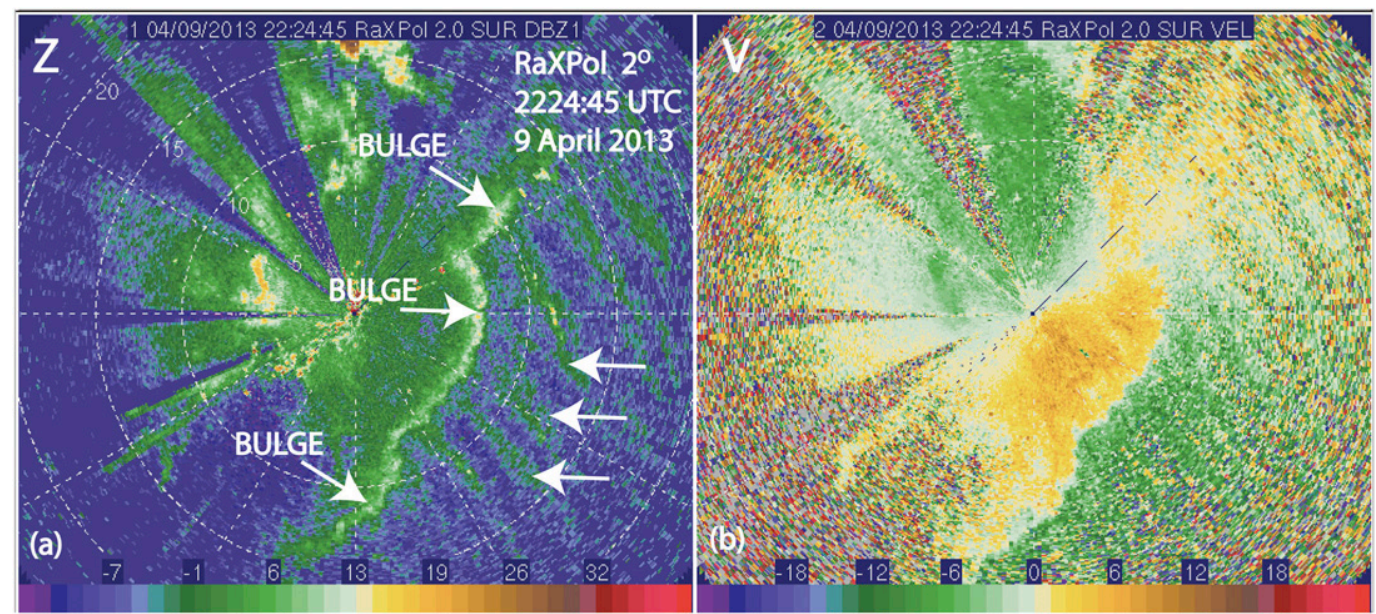

FIG. 18. As in Fig. 17, but at 2224:45 UTC, while the cold front was moving away, and at $2^{\circ}$ elevation angle. Bowed segments (bulges) in the fine line are marked. Beam blockage from nearby ground clutter is evident in some azimuthal sections, particularly in the sector from west-southwest to north-northwest of the radar. 

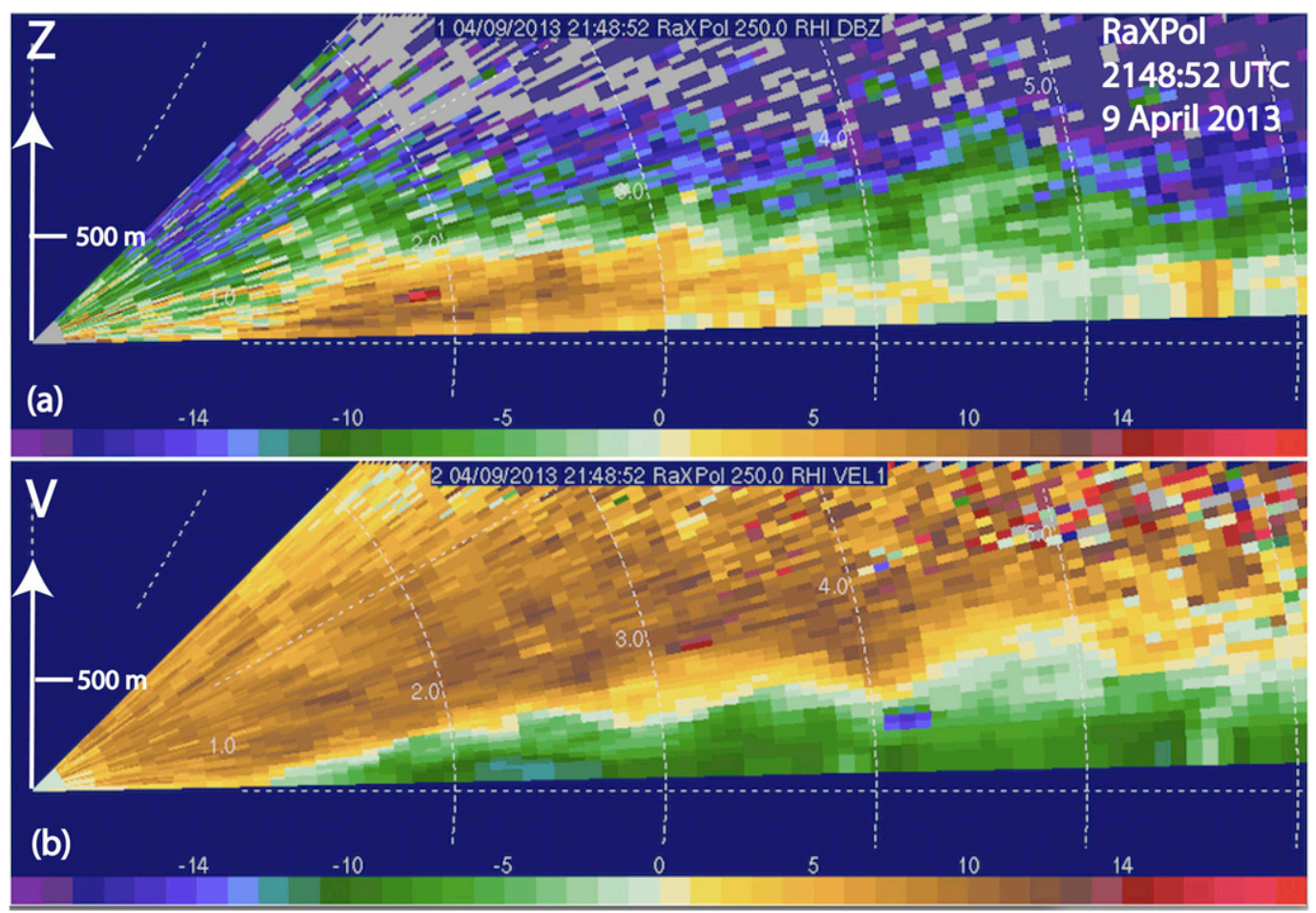

FIG. 19. Vertical cross sections at low levels through the leading edge of the cold front at 2148:52 UTC 9 Apr 2013 of (a) radar reflectivity factor $\left(Z_{\mathrm{H}} ; \mathrm{dB} Z\right)$ and (b) Doppler velocity $\left(V ; \mathrm{m} \mathrm{s}^{-1}\right)$.

polarimetric field; for example, this variability can be seen in Fig. 6 by comparing mean values of $Z_{\mathrm{DR}}$ and $\rho_{\mathrm{hv}}$ (and, not shown, $\delta$ as implied in $\Phi_{\mathrm{DP}}$ ) west of the radar to those north of the radar ahead of the fine line. Thus, it is hypothesized that the prefrontal wind-shift line, which is associated with the convergent shift in wind direction, "trapped" insects or birds and was readily identified on polarimetric surveillance radars, and may not have been associated with strong gradients in the moisture and temperature fields.

\section{APPENDIX C}

\section{Dual-Doppler Analysis Methodology}

The fine-line associated with the PWL (see section 3b) fell within one of the lobes of dual-Doppler coverage (areas where the between-beam angle is greater than $30^{\circ}$ and less than $150^{\circ}$ ) when the PWL was located to the west, northwest, and north of Norman (Fig. 9a).

The dual-Doppler wind syntheses were created by first objectively analyzing the raw RaXPol and KTLX data and mapping them to a Cartesian grid using a two-pass Barnes analysis (Barnes 1964) with a second-pass convergence parameter of 0.3 (Majcen et al. 2008). To determine the parameters for objective analysis such as the grid spacing and smoothing parameters, a conservative estimate based on the maximum distance of the fine line from the radar, not the maximum size of the domain, was used. More specifically, the vertical and horizontal grid spacing was calculated using $\delta=\Delta / 2.5$, where $\Delta$ represents the raw data spacing and $\delta$ represents the grid spacing in Cartesian coordinates (Koch et al. 1983), resulting in $\delta_{x, y}=250 \mathrm{~m}$ and $\delta_{z}=100 \mathrm{~m}$. Horizontal and vertical smoothing parameters were then obtained through the use of the equation $\kappa=(1.33 \Delta)^{2}$, consistent with Pauley and $\mathrm{Wu}(1990)$, where $\kappa$ is the degree of smoothing. In this case $\kappa_{x, y}=$ $0.25 \mathrm{~km}^{2}$ and $\kappa_{z}=0.15 \mathrm{~km}^{2}$, both of which of which were calculated with respect to the farthest radarobserved feature in the fine line, not the edge of the dual-Doppler domain, as to avoid oversmoothing features within the area of interest. Vertical velocities were then obtained through upward integration of the anelastic mass continuity equation and a lower boundary condition of $w=0$. Extrapolation of data below the minimum beam height AGL (i.e., $191 \mathrm{~m}$ ) were not considered in this analysis. 


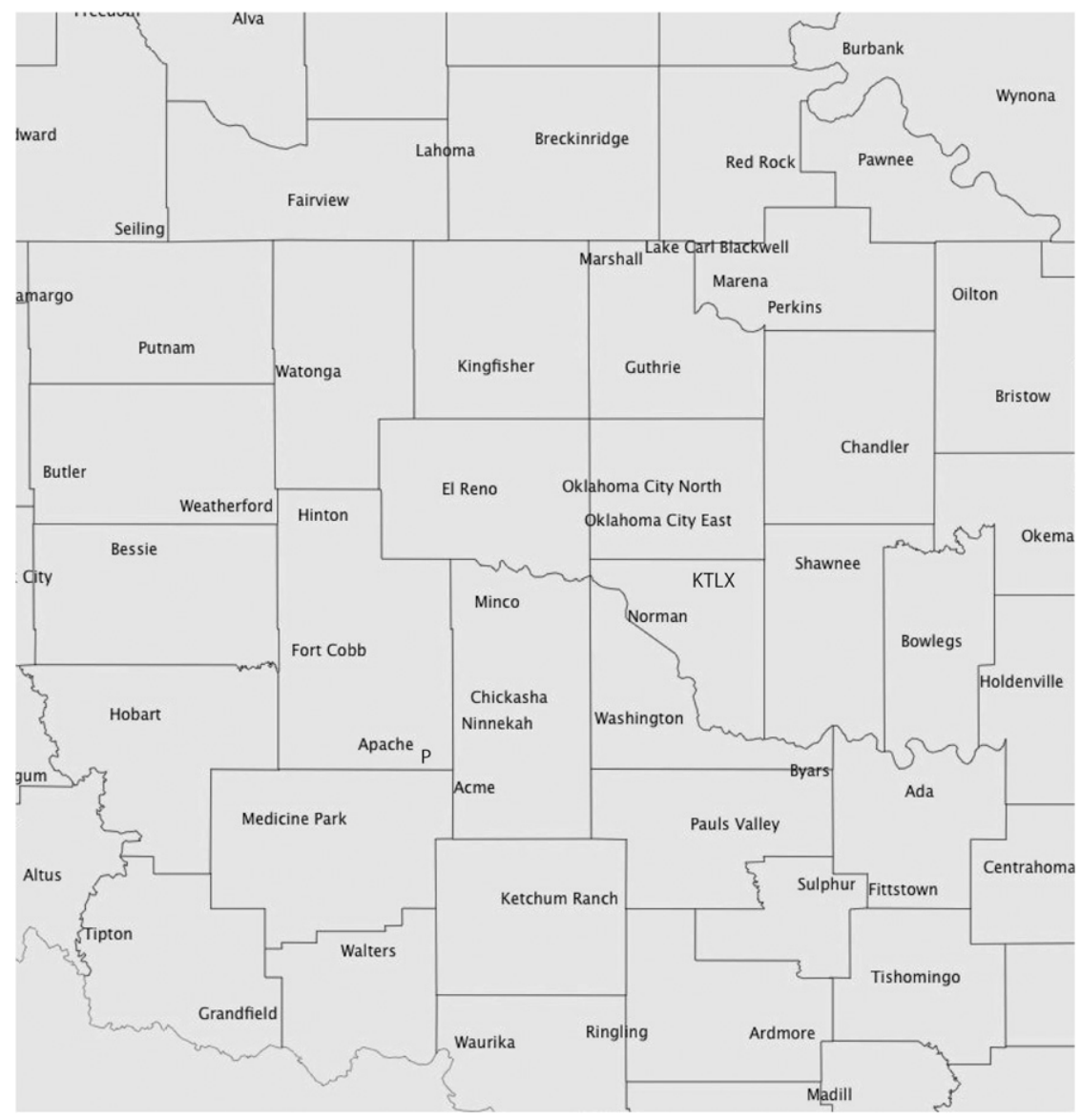

FIG. A1. A map of portions of central and west-central Oklahoma showing mesonet sites, county boundaries, KTLX, and the location (P) southeast of Apache of the photograph shown in Fig. 15.

\section{REFERENCES}

Barnes, S. L., 1964: A technique for maximizing details in numerical weather map analysis. J. Appl. Meteor., 3, 396-409, doi:10.1175/1520-0450(1964)003<0396:ATFMDI>2.0.CO;2.

Betts, A. K., 1984: Boundary layer thermodynamics of a High Plains severe storm. Mon. Wea. Rev., 112, 2199-2211, doi:10.1175/1520-0493(1984)112<2199:BLTOAH>2.0.CO;2.

Bluestein, H. B., 1992: Synoptic-Dynamic Meteorology in Midlatitudes. Vol. I, Observations and Theory of Weather Systems, Oxford University Press, $431 \mathrm{pp}$.

-1993: Synoptic-Dynamic Meteorology in Midlatitudes. Vol. II, Observations and Theory of Weather Systems, Oxford University Press, $594 \mathrm{pp}$.

— convective phenomena with a mobile, 3-mm wavelength, Doppler radar: The spring 1999 field experiment. Bull. Amer. Meteor. Soc., 81, 2939-2951, doi:10.1175/1520-0477(2000)081<2939: OOTAOC $>2.3 . \mathrm{CO} ; 2$.

— , and J. C. Snyder, 2015: An observational study of the effects of dry air produced in dissipating convective storms on the predictability of severe weather. Wea. Forecasting, 30, 79-114, doi:10.1175/WAF-D-14-00065.1.
,-- , and J. B. Houser, 2015: A multiscale overview of the El Reno, Oklahoma, tornadic supercell of 31 May 2013. Wea. Forecasting, 30, 525-552, doi:10.1175/WAF-D-14-00152.1.

Blumberg, W. G., D. D. Turner, U. Löhnert, and S. Castleberry, 2015: Ground-based temperature and humidity profiling using spectral infrared and microwave observations. Part II: Actual retrieval performance in clear-sky and cloudy conditions. J. Appl. Meteor. Climatol., 54, 2305-2319, doi:10.1175/ JAMC-D-15-0005.1.

Bringi, V. N., and V. Chandrasekar, 2001: Polarimetric Doppler Weather Radar: Principles and Applications. Cambridge University Press, $636 \mathrm{pp}$.

Brock, F. V., K. Crawford, R. Elliott, G. Cuperus, S. Stadler, H. Johnson, and M. Eilts, 1995: The Oklahoma Mesonet: A technical overview. J. Atmos. Oceanic Technol., 12, 5-19, doi:10.1175/1520-0426(1995)012<0005:TOMATO>2.0.CO;2.

Brunt, D., 1934: Physical and Dynamical Meteorology. Cambridge University Press, $411 \mathrm{pp}$.

Buban, M. S., and C. L. Ziegler, 2016: The formation of small-scale atmospheric vortices via horizontal shearing instability. J. Atmos. Sci., 73, 2061-2084, doi:10.1175/JAS-D-14-0355.1.

Cohen, R. A., and D. M. Schultz, 2005: Contraction rate and its relationship to frontogenesis, the Lyapunov exponent, fluid 
trapping, and airstream boundaries. Mon. Wea. Rev., 133, 1353-1369, doi:10.1175/MWR2922.1.

Coleman, T. A., K. R. Knupp, and D. Herzmann, 2009: The spectacular undular bore in Iowa on 2 October 2007. Mon. Wea. Rev., 137, 495-503, doi:10.1175/2008MWR2518.1.

Crook, N. A., 1988: Trapping of low-level internal gravity waves. J. Atmos. Sci., 45, 1533-1541, doi:10.1175/ 1520-0469(1988)045<1533:TOLLIG > 2.0.CO;2.

Crum, T. D., and R. L. Alberty, 1993: The WSR-88D and the WSR-88D Operational Support Facility. Bull. Amer. Meteor. Soc., 74, 1669-1687, doi:10.1175/1520-0477(1993)074<1669: TWATWO $>2.0 . \mathrm{CO} ; 2$.

Cunningham, P., and D. Keyser, 1999: Frontogenesis and frontal motion due to confluent deformation with a translating dilatation axis. Quart. J. Roy. Meteor. Soc., 125, 2563-2573, doi:10.1002/qj.49712555911.

Doviak, R. J., and D. S. Zrnić, 1993: Doppler Radar and Weather Observations. 2nd ed. Dover Publications, 562 pp.

Hanstrum, B. N., K. J. Wilson, and S. L. Barrell, 1990: Prefrontal troughs over southern Australia. Part I: A climatology. Wea. Forecasting, 5, 22-31, doi:10.1175/1520-0434(1990)005<0022: PTOSAP $>2.0 . \mathrm{CO} ; 2$.

Hartung, D. C., J. A. Otkin, J. E. Martin, and D. D. Turner, 2010: The life cycle of an undular bore and its interaction with a shallow intense cold front. Mon. Wea. Rev., 138, 886-908, doi:10.1175/2009MWR3028.1.

Houser, J. L., and H. B. Bluestein, 2011: Polarimetric Doppler radar observations of Kelvin-Helmholtz waves in a winter storm. J. Atmos. Sci., 68, 1676-1702, doi:10.1175/2011JAS3566.1.

- — - and J. C. Snyder, 2015: Rapid-scan, polarimetric, Doppler radar observations of tornadogenesis and tornado dissipation in a tornadic supercell: The "El Reno, Oklahoma" storm of 24 May 2011. Mon. Wea. Rev., 143, 2685-2710, doi:10.1175/MWR-D-14-00253.1.

Hutchinson, T. A., and H. B. Bluestein, 1998: Prefrontal wind-shift lines in the plains of the United States. Mon. Wea. Rev., 126, 141-166, doi:10.1175/1520-0493(1998)126<0141:PWSLIT>2.0.CO;2.

Keyser, D., 1986: Atmospheric fronts: An observational perspective. Mesoscale Meteorology and Forecasting, P. S. Ray, Ed., Amer. Meteor. Soc., 216-258.

Klemp, J. B., R. Rotunno, and W. C. Skamarock, 1997: On the propagation of internal bores. J. Fluid Mech., 331, 81-106, doi:10.1017/S0022112096003710.

Knight, C. A., and L. J. Miller, 1993: First radar echoes from cumulus clouds. Bull. Amer. Meteor. Soc., 74, 179-188, doi:10.1175/1520-0477(1993)074<0179:FREFCC>2.0.CO;2.

Knuteson, R. O., and Coauthors, 2004: Atmospheric Emitted Radiance Interferometer. Part II: Instrument performance. J. Atmos. Oceanic Technol., 21, 1777-1789, doi:10.1175/ JTECH-1663.1.

Koch, S. E., and W. L. Clark, 1999: A nonclassical cold front observed during COPS-91: Frontal structure and the process of severe storm initiation. J. Atmos. Sci., 56, 2862-2890, doi:10.1175/1520-0469(1999)056<2862:ANCFOD>2.0.CO;2.

_- M. Desjardins, and P. J. Kocin, 1983: An interactive Barnes objective map analysis scheme for use with satellite and conventional data. J. Climate Appl. Meteor., 22, 1487-1503, doi:10.1175/1520-0450(1983)022<1487:AIBOMA > 2.0.CO;2.

— C. Flamant, J. W. Wilson, B. M. Gentry, and B. D. Jamison, 2008: An atmospheric soliton observed with Doppler radar, differential absorption lidar, and a molecular Doppler lidar. J. Atmos. Oceanic Technol., 25, 1267-1287, doi:10.1175/ 2007JTECHA951.1.
Ligda, M. G. H., and S. G. Bigler, 1958: Radar echoes from a cloudless cold front. J. Meteor., 15, 494-501, doi:10.1175/ 1520-0469(1958)015<0494:REFACC $>2.0 . C O ; 2$.

Majcen, M., P. Markowski, Y. Richardson, D. Dowell, and J. Wurman, 2008: Multipass objective analyses of Doppler radar data. J. Atmos. Oceanic Technol., 25, 1845-1858, doi:10.1175/2008JTECHA1089.1.

Martin, H. C., 1973: Some observations of the microstructure of dry cold fronts. J. Appl. Meteor., 12, 658-663, doi:10.1175/ 1520-0450(1973)012<0658:SOOTMO > 2.0.CO;2.

Martin, W. J., and A. Shapiro, 2007: Discrimination of bird and insect radar echoes in clear air using high-resolution radars. J. Atmos. Oceanic Technol., 24, 1215-1230, doi:10.1175/ JTECH2038.1.

McPherson, R. A., and Coauthors, 2007: Statewide monitoring of the mesoscale environment: A technical update on the Oklahoma Mesonet. J. Atmos. Oceanic Technol., 24, 301-321, doi:10.1175/JTECH1976.1.

Melnikov, V. M., R. J. Doviak, D. S. Zrnić, and D. J. Stensrud, 2011: Mapping Bragg scatter with a polarimetric WSR-88D. J. Atmos. Oceanic Technol., 28, 1273-1285, doi:10.1175/ JTECH-D-10-05048.1.

Pauley, P. M., and X. Wu, 1990: The theoretical, discrete, and actual response of the Barnes objective analysis scheme for one- and two-dimensional fields. Mon. Wea. Rev., 118, 1145-1164, doi:10.1175/1520-0493(1990)118<1145: TTDAAR $>2.0 . \mathrm{CO} ; 2$.

Pazmany, A. L., J. B. Mead, H. B. Bluestein, J. C. Snyder, and J. B. Houser, 2013: A mobile, rapid-scanning, X-band, polarimetric (RaXPol) Doppler radar system. J. Atmos. Oceanic Technol., 30, 1398-1413, doi:10.1175/JTECH-D-12-00166.1.

Ralph, F. M., 1995: Using radar-measured radial vertical velocities to distinguish precipitation scattering from clear-air scattering. J. Atmos. Oceanic Technol., 12, 257-267, doi:10.1175/ 1520-0426(1995)012<0257:URMRVV>2.0.CO;2.

Rottman, J., and J. Simpson, 1989: The formation of internal bores in the atmosphere: A laboratory model. Quart. J. Roy. Meteor. Soc., 115, 941-963, doi:10.1002/qj.49711548809.

Sanders, F., 1999: A proposed method of surface map analysis. Mon. Wea. Rev., 127, 945-955, doi:10.1175/1520-0493(1999)127<0945: APMOSM $>2.0 . \mathrm{CO} ; 2$. , and C. A. Doswell III, 1995: A case for detailed surface analysis. Bull. Amer. Meteor. Soc., 76, 505-521, doi:10.1175/ 1520-0477(1995)076<0505:ACFDSA $>2.0 . C O ; 2$.

Schultz, D. M., 2004: Cold fronts with and without prefrontal wind shifts in the central United States. Mon. Wea. Rev., 132, 2040-2053, doi:10.1175/1520-0493(2004)132<2040: CFWAWP $>2.0 . \mathrm{CO} ; 2$.

- 2005: A review of cold fronts with prefrontal troughs and wind shifts. Mon. Wea. Rev., 133, 2449-2472, doi:10.1175/ MWR2987.1.

2008: Perspectives on Fred Sanders' research on cold fronts. Synoptic-Dynamic Meteorology and Weather Analysis and Forecasting: A Tribute to Fred Sanders, Meteor. Monogr., No. 55, Amer. Meteor. Soc., 109-126.

- and P. J. Roebber, 2008: The fiftieth anniversary of Sanders (1955): A mesoscale model simulation of the cold front of 1718 April 1953. Synoptic-Dynamic Meteorology and Weather Analysis and Forecasting: A Tribute to Fred Sanders, Meteor. Monogr., No. 55, Amer. Meteor. Soc., 127-143.

Scorer, R. S., 1949: Theory of waves in the lee of mountains. Quart. J. Roy. Meteor. Soc., 75, 41-56, doi:10.1002/ qj.49707532308. 
Shapiro, M. A., 1984: Meteorological tower measurements of a surface cold front. Mon. Wea. Rev., 112, 1634-1639, doi:10.1175/ 1520-0493(1984)112<1634:MTMOAS > 2.0.CO;2.

Simpson, J. E., 1982: Gravity currents in the laboratory, atmosphere, and ocean. Annu. Rev. Fluid Mech., 14, 213-234, doi:10.1146/ annurev.fl.14.010182.001241.

Snyder, J. C., and H. B. Bluestein, 2014: Some considerations for the use of high-resolution mobile radar data in tornado intensity determination. Wea. Forecasting, 29, 799-827, doi:10.1175/WAF-D-14-00026.1.

Stonitsch, J. R., and P. M. Markowski, 2007: Unusually long duration, multiple-Doppler radar observations of a front in a convective boundary layer. Mon. Wea. Rev., 135, 93-117, doi:10.1175/MWR3261.1.

Turner, D. D., and U. Löhnert, 2014: Information content and uncertainties in thermodynamic profiles and liquid cloud properties retrieved from the ground-based Atmospheric Emitted Radiance Interferometer (AERI). J. Appl. Meteor. Climatol., 53, 752-771, doi:10.1175/JAMC-D-13-0126.1.

, W. F. Feltz, and R. A. Ferrare, 2000: Continuous water vapor profiles from operational ground-based active and passive remote sensors. Bull. Amer. Meteor. Soc., 81, 1301-1317, doi:10.1175/1520-0477(2000)081<1301:CWBPFO>2.3.CO;2.

- , R. O. Knuteson, H. E. Revercomb, C. Lo, and R. G. Dedecker, 2006: Noise reduction of Atmospheric Emitted Radiance Interferometer (AERI) observations using principal component analysis. J. Atmos. Oceanic Technol., 23, 12231238, doi:10.1175/JTECH1906.1.

Ungarish, M., 2009: An Introduction to Gravity Currents and Intrusions. CRC Press, 489 pp.

Wakimoto, R. M., and H. Cai, 2002: Airborne observations of a front near a col during FASTEX. Mon. Wea. Rev.,
130, 1898-1912, doi:10.1175/1520-0493(2002)130<1898: AOOAFN $>2.0 . \mathrm{CO} ; 2$.

Weckwerth, T. M., J. W. Wilson, R. M. Wakimoto, and N. A. Crook, 1997: Horizontal convective rolls: Determining the environmental conditions supporting their existence and characteristics. Mon. Wea. Rev., 125, 505-526, doi:10.1175/ 1520-0493(1997)125<0505:HCRDTE > 2.0.CO;2.

Wilson, J. W., and W. E. Schreiber, 1986: Initiation of convective storms at radar-observed boundary-layer convergence lines. Mon. Wea. Rev., 114, 2516-2536, doi:10.1175/ 1520-0493(1986)114<2516:IOCSAR > 2.0.CO;2.

—, T. M. Weckwerth, J. Vivekanandan, R. M. Wakimoto, and R. W. Russell, 1994: Boundary layer clear-air radar echoes: Origin of echoes and accuracy of derived winds. J. Atmos. Oceanic Technol., 11, 1184-1206, doi:10.1175/1520-0426(1994)011<1184: BLCARE $>2.0 . \mathrm{CO} ; 2$.

Wurman, J., and S. Gill, 2000: Finescale radar observations of the Dimmitt, Texas (2 June 1995), tornado. Mon. Wea. Rev., 128, 2135-2164, doi:10.1175/1520-0493(2000)128<2135: FROOTD $>2.0 . \mathrm{CO} ; 2$.

Ziegler, C. L., E. N. Rasmussen, M. S. Buban, Y. P. Richardson, L. J. Miller, and R. M. Rabin, 2007: The "triple point" on 24 May 2002 during IHOP. Part II: Ground-radar and in situ boundary layer analysis of cumulus development and convection initiation. Mon. Wea. Rev., 135, 2443-2472, doi:10.1175/ MWR3411.1.

Zrnić, D. S., and A. V. Ryzhkov, 1998: Observations of insects and birds with a polarimetric radar. IEEE Trans. Geosci. Remote Sens., 36, 661-668, doi:10.1109/36.662746.

, and —-1999: Polarimetry for weather surveillance radars. Bull. Amer. Meteor. Soc., 80, 389-406, doi:10.1175/ 1520-0477(1999)080<0389:PFWSR>2.0.CO;2. 